\title{
MODELLING STRESS-STRAIN RELATIONS OF SAND
}

\author{
Fumio Tatsuoka ${ }^{\mathrm{i})}$, Mohammed S. A. Siddiquee ${ }^{\mathrm{ii})}$, Choon-Sik Park ${ }^{\mathrm{iii})}$, \\ MAKoto SAKAMOTO ${ }^{\text {iv) }}$ and FumihiRo $\mathrm{ABE}^{\mathrm{v})}$
}

\begin{abstract}
A modelling method for highly nonlinear shear stress-strain relations in plane strain compression of a fine sand, Toyoura Sand, which has been used extensively in a large number of model tests by many researchers, is attempted taking into account the effects of many major factors; (1) void ratio, (2) confining pressure $\sigma_{3}$, (3) the initial and maximum shear modulus $G_{\max }$ as observed at strains less than about $0.001 \%$, (4) anisotropic strength and deformation characteristics, (5) strain softening associated with strain localization into a shear band, and (6) the stress ratio during consolidation. The model is based on a modified hyperbolic equation. By the model proposed, a relation from very small strain $(0.0001 \%)$ to the residual conditions through smooth transition from pre-peak to post-peak relations can be generated for a given condition. A generated stress-strain relation has a tangent modulus which is continuous at the peak strength state between the pre-peak and post-peak parts.
\end{abstract}

Key words: anisotropy, plane strain compression, sand, shear strength, stress-strain curve (IGC: D6/E13)

\section{INTRODUCTION}

For any rational numerical analysis, for example by FEM, of model tests using a sand, the fully formulated pre-peak and post-peak stress-strain relationships of the sand including the peak strength properties are necessary. For example, in Geotechnical Engineering Laboratory of Institute of Industrial Science, University of Tokyo, a longterm study into the bearing capacity of footing on sand has been performed by using only one kind of sand (Toyoura Sand) for the last decade. Toyoura Sand is a quartz-rich poorly graded fine sand having a sub-angular particle shape with $D_{50}=0.16 \mathrm{~mm}, \quad U_{c}=1.46$, $G_{s}=2.64, e_{\max }=0.977$ and $e_{\min }=0.605$. This program includes a comprehensive series of triaxial compression (TC) tests, plane strain compression (PSC) tests (e.g., Tatsuoka et al., 1986) and torsional simple shear tests, plane strain model tests in $1 \mathrm{~g}$ and in a centrifuge and their FEM simulation (Tatsuoka et al., 1991; Siddiquee et al., 1991, 1992). In particular, model tests using a footing of $0.5 \mathrm{~m}$ in width and $2.0 \mathrm{~m}$ in length are the largest plane strain

i) Professor, Institute of Industrial Science, University of Tokyo, Roppongi, Minato-ku, Tokyo.

ii) Graduate student, Institute of Industrial Science, University of Tokyo.

iii) Researcher, Ocean Resources Research Institute, Dong-A University, Pusan, Korea.

Formerly Graduate Student, University of Tokyo.

iv) Ministry of Construction, Formerly Graduate Student, University of Tokyo.

v) Tokyo Metropolitan Government, Formerly Graduate Student, University of Tokyo.

Manuscript was received for review on July 9, 1992.

Written discussions on this paper should be submitted before January 1, 1994 to the Japanese Society of Soil Mechanics and Foundation Engineering, Sugayama Bldg. 4 F, Kanda Awaji-cho 2-23, Chiyoda-ku, Tokyo 101, Japan. Upon request the closing date may be extended one month. 
tests of this kind so far performed in the world.

In this study, inherent anisotropy in the strength and deformation characteristics of air-pluviated sand, which was first revealed by Oda (1972) and Arthur and Menzies (1972), was fully taken into account in modelling the prepeak stress-strain relations and peak strength in PSC. It is only recently in the authors' laboratory, however, we have become able to measure small axial strains locally on the lateral surface of specimen which are totally free from the bedding error (BE) effects (Goto et al., 1991). BE is due to the extra deformation which occurs at the ends of specimen, other than the homogeneous deformation of specimen. $\mathrm{BE}$ in terms of axial strain $\left(\varepsilon_{1}\right)_{B E}$ is defined as the difference between the axial strain obtained from the movement of the specimen cap and the local axial strain averaged for the central part of specimen where the deformation is rather homogeneous. Then $\mathrm{BE}$ at the top and bottom ends in terms of axial deformation $\triangle_{B E}$ is $\left(\varepsilon_{1}\right)_{B E}$ multiplied by the specimen height. When the effective confining pressure changes, the volume change of specimen obtained from the amount of water which is expelled from or sucked into the specimen may involve an error due to the indentation of lateral membrane into the room between soil particles located next to the lateral surface of specimen. This is called the membrane penetration (MP). Note that $\mathrm{BE}$ at the top and bottom ends of specimen also causes an error in the measured volume change of specimen, for which the mechanism is similar to that for MP at the lateral surface of specimen. Therefore, errors are involved in the lateral strain obtained from the volume change of specimen and the axial strain in TC and PSC tests. Another important issue is strain localization (e.g., Tatsuoka et al., 1990, 1991), and will be discussed to some extent in this paper.

The only data set of PSC tests of Toyoura Sand currently available to the authors which not only covers a wide range of density and pressure level, but also has fully examined inherent anisotropy in the strength and deformation characteristics is the one reported by
Tatsuoka et al. (1986). In these PSC tests, the specimens had dimensions of $10.5 \mathrm{~cm}$ high, 8 $\mathrm{cm}$ long and $4 \mathrm{~cm}$ wide in the $\sigma_{3}$ direction. They were prepared by pluviating air-dried sand particles through air as for the model tests, and normally consolidated isotropically to different prescribed confining pressures. The top and bottom ends and the lateral surfaces ( $\sigma_{2}$-planes) were lubricated with a $50 \mu \mathrm{m}$ thick layer of Dow high-vacuum silicone grease and a $200 \mu$ m-thick latex membrane with a Young's modulus of $15 \mathrm{kgf} / \mathrm{cm}^{2}(1.5$ $\mathrm{MPa}$ ) (Type 1 lubrication layer; the details are given in Tatsuoka et al., 1984). The same lubrication method was used in all the tests reported in this paper. Therefore, both the axial strain obtained from the movement of the specimen cap and the volumetric strain obtained from the amount of water expelled from and sucked into the specimen included $\mathrm{BE}$ and MP effects. Despite the above, it was considered that until we obtain a more systematic and very reliable data set by measuring the axial and lateral strains directly and locally on the lateral surface of specimen by means of a local gauge, this data set of the PSC tests should be used for the numerical analyses of model tests using Toyoura Sand after modelling in an appropriate way, while correcting them for the BE and MP effects.

Herein presented is the method and results of modelling shear stress-shear strain relationships obtained from the PSC tests performed under different constant confining pressures $\sigma_{3}$ reported by Tatsuoka et al. (1986). Other aspects, dilatancy characteristics, the deformation under isotropic and anisotropic compression are discussed to some extent in Tatsuoka et al. (1991), Siddiquee (1991) and Siddiquee et al. (1991, 1992), and are beyond the scope of this paper.

\section{BEDDING ERROR}

A study into the BE and MP effects was performed by Goto (1987) and Goto et al. (1991) by using different sizes of triaxial specimens having a range of height from $2.0 \mathrm{~cm}$ to $60 \mathrm{~cm}$ and a range of diameter from $5 \mathrm{~cm}$ to $30 \mathrm{~cm}$. $\mathrm{He}$ also evaluated directly the amount of $\left(\varepsilon_{1}\right)_{B E}$ 
in TC tests by measuring both the axial movement of the specimen cap and the local axial deformation along the lateral surface. The latter was obtained by means of the LDT (Local Deformation Transducer, Goto et al., 1991). Nakamura (1987) evaluated the amount of $\left(\varepsilon_{1}\right)_{B E}$ in PSC tests by measuring to an accuracy of $0.005 \mathrm{~mm}$ the local deformation on the lateral surface (the $\sigma_{2}$ plane) of specimen by means of the laser speckling method (Tatsuoka et al., 1990), and confirmed the results of Goto (1987). Abe (1989) reconfirmed the results of Goto and Nakamura by measuring the local axial deformation along the lateral surface of PSC specimen by means of LDT. Figs. 1 and 2 show the values of $\Delta_{B E}$ for loose and dense specimens of Toyoura Sand in PSC tests at a constant confining pressure $\sigma_{3}$ equal to $0.1,0.5$ and $0.8 \mathrm{kgf} / \mathrm{cm}^{2}(9.8,49.0$ and $78.5 \mathrm{kPa}$ ), obtained by Abe (1989). It may be seen from Figs. 1 and 2 that $\Delta_{B E}$ increases with the shear stress level in each test and with $\sigma_{3}$, namely $\Delta_{B E}$ increases with the axial stress $\sigma_{1}$. This would be due to that as $\sigma_{1}$ increases, all the four factors increase, which are the compression of thin relatively loose sand layers formed next to the specimen boundaries, the

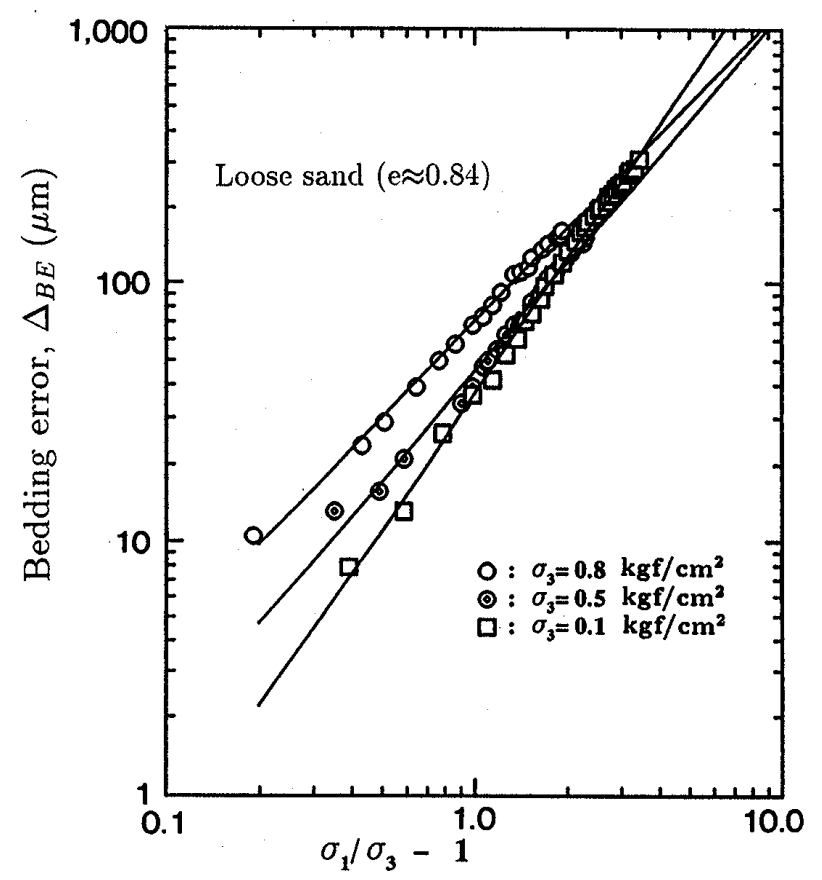

Fig. 1. Linear regression of $\Delta_{B E}$ versus $\sigma_{3}$ relation in full logarithmic scale for different $\sigma_{3}$ (Loose sand) indentation of sand particle into a lubrication layer, the squeezing out of grease, and the compression of rubber sheet. Note, however, that $\Delta_{B E}$ is a function of not only $\sigma_{1}$, but also $\sigma_{1} / \sigma_{3}$ (Goto, 1987). He showed that at the same $\sigma_{1}, \Delta_{B E}$ is larger at a higher $\sigma_{1} / \sigma_{3}$ (as can be seen from Fig. 1 and 2), probably due to that the effects of the last two of the abovementioned four factors increase with $\sigma_{1} / \sigma_{3}$. It may also be seen from Figs. 1 and 2 that with the others being the same, $\Delta_{B E}$ is larger for the looser specimens. The reason is not known to the present authors.

Considering the above and since the PSC tests started from $\sigma_{1} / \sigma_{3}=1$, the curves shown in Figs. 1 and 2 were modelled as:

$$
\Delta_{B E}=10^{a} \cdot\left\{\left(\frac{\sigma_{1}}{\sigma_{3}}\right)-1\right\}^{b}
$$

in which $\boldsymbol{a}$ and $\boldsymbol{b}$ are the powers, and $\Delta_{B E}$ in $\mu \mathrm{m}$. From the observation of the data, $a$ showed a tendency to be a function of $\sigma_{3}$ and $\boldsymbol{b}$ be a function of void ratio, $\boldsymbol{e}$. The values of $\boldsymbol{a}$ and $\boldsymbol{b}$ for each PSC test were determined by a linear regression analysis in log-log plotting shown in Figs. 1 and 2, and based on them, the functions were determined by the least

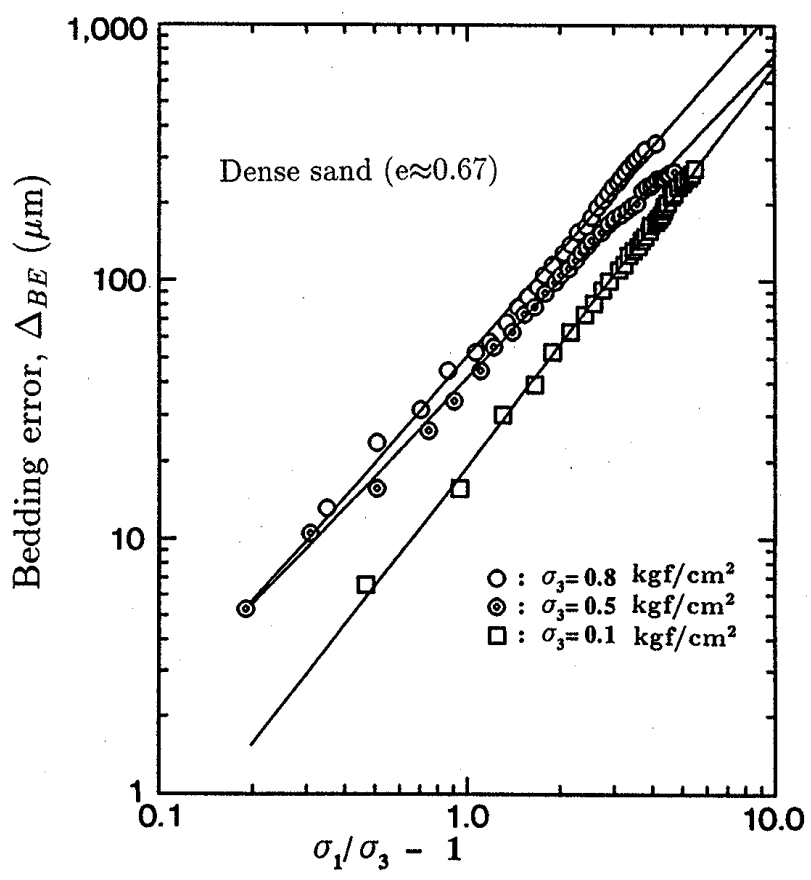

Fig. 2. Linear regression of $\Delta_{B E}$ versus $\sigma_{3}$ relation in full logarithmic scale for different $\sigma_{3}$ (Dense sand) 
mean square method as:

$a=1.3803+0.5046 \cdot \sigma_{3} \quad\left(\sigma_{3}\right.$ in $\left.\mathrm{kgf} / \mathrm{cm}^{2}\right)$

$b=1.1931+0.3097 \cdot e$

The $\Delta_{B E}$ value should have an upper bound because of the limited thickness of the grease and latex layers, which is in total $0.25 \mathrm{~mm}$ $(0.05 \mathrm{~mm}$ plus $0.2 \mathrm{~mm}$ ) for one end. So, an upper limit of the $\Delta_{B E}$ value of $0.5 \mathrm{~mm}(500 \mu \mathrm{m})$ was used in the following analysis. Since the amount of the data presented in Figs. 1 and 2 is limited, obviously further study will be needed to refine the relationships.

On the other hand, in these PSC tests, the intermediate principal strain $\varepsilon_{2}$ was not exactly zero because of the effect of $\mathrm{BE}$ on the $\sigma_{2}$ planes, but $\varepsilon_{2}$ was equal to $-\left(\Delta \varepsilon_{2}\right)_{B E}$ (the strain due to the $\mathrm{BE}$ effect). Thus, the corrected value of $\gamma=\varepsilon_{1}-\varepsilon_{3}$ is obtained as:

$$
\begin{aligned}
\gamma= & \varepsilon_{1}-\varepsilon_{3} \\
= & 2 \varepsilon_{1}-\varepsilon_{v}+\varepsilon_{2} \\
= & 2\left\{\left(\varepsilon_{1}\right)_{\text {measured }}-\left(\Delta \varepsilon_{1}\right)_{B E}\right\} \\
& -\left\{\left(\varepsilon_{v}\right)_{\text {measured }}-\left(\varepsilon_{v}\right)_{B E}\right\}-\left(\Delta \varepsilon_{2}\right)_{B E} \\
= & 2\left\{\left(\varepsilon_{1}\right)_{\text {measured }}\right\}-\left(\varepsilon_{v}\right)_{\text {measured }}-\text { Error } \\
= & \gamma_{\text {measured }}-\text { Error }
\end{aligned}
$$

Hence,

$$
\text { Error }=2\left(\Delta \varepsilon_{1}\right)_{B E}+\left(\Delta \varepsilon_{2}\right)_{B E}-\left(\Delta \varepsilon_{v}\right)_{B E}
$$

In Eq. (5), the term Error is the correction needed to obtain the corrected value of $\gamma$, and each term of which can be obtained as follows, considering that $\Delta_{B E}$ by Eq. (1) is for two ends.

$$
\begin{aligned}
\left(\Delta \varepsilon_{1}\right)_{B E} & =\frac{\left(\Delta_{B E}\right. \text { by Eq. 1) }}{(\text { the specimen height, } H)} \\
\left(\Delta \varepsilon_{2}\right)_{B E} & =\frac{\left(\Delta_{B E} \text { by Eq. } 1\right)}{(\text { the specimen length, } L)} \\
\left(\Delta \varepsilon_{v}\right)_{B E} & =\frac{2 \Delta l_{1}}{H}+\frac{2 \Delta l_{2}}{L}
\end{aligned}
$$

For Eq. (7), $\sigma_{1} / \sigma_{3}$ in Eq. (1) is replaced with $\sigma_{2} / \sigma_{3}$. The terms $\Delta l_{1}$ and $\Delta l_{2}$ are the volume change per unit area on one surface due to the $B E$ effect. Since the mechanism of the volume change due to $\mathrm{BE}$ can be considered similar to that due to MP (Goto, 1987), it was assumed in this study that $\Delta l_{1}$ and $\Delta l_{2}$ have the same function with that for the amount of MP, $\Delta_{M P}$. For the change in the effective pressure from $p_{0}$ to $p$ applied on the membrane concerned, $\Delta_{M P}$ per unit area for one surface has been given by Goto (1987) as:

$$
\Delta_{\mathrm{MP}}=1.7 * 10^{-3} * \log _{10}\left(\frac{p}{p_{0}}\right)\left(\mathrm{cm}^{3} / \mathrm{cm}^{2}\right)
$$

Therefore, we obtain:

$$
\begin{aligned}
& \frac{\Delta l_{1}}{H}=1.7 * 10^{-3} * \log _{10}\left(\frac{\sigma_{1}}{\sigma_{10}}\right) / H \\
& \frac{\Delta l_{2}}{L}=1.7 * 10^{-3} * \log _{10}\left(\frac{\sigma_{2}}{\sigma_{20}}\right) / L
\end{aligned}
$$

Note that Eqs. (9), (10) and (11) are valid only for Toyoura Sand with one latex membrane having a Young's modulus of $15 \mathrm{kgf} / \mathrm{cm}^{2}$ and a thickness of $0.3 \mathrm{~mm}$. All the values of shear strain $(\gamma)$ shown herein for the PSC tests have been corrected by using Eqs. (5) through (11).

\section{HYPERBOLIC EQUATION}

It is known that the Conventional Hyperbolic Equation (CHE) cannot fit the whole stress-strain relationship for a wide range of strain, say from $0.0001 \%$ to that at the peak stress state $(1-10 \%)$, for most geotechnical engineering materials including soft clays, sands and soft rocks (Shibuya et al., 1991a; Tatsuoka and Shibuya, 1992). In particular, the CHE underestimates the non-linearity of stress-strain relation of normally consolidated uncemented soils. At small strains, it usually exhibits poor performance. However, the CHE is still convenient for the purpose of modelling part of a given stress-strain relation for a limited range of strain; usually for a larger strain range, especially near the peak stress state. On the other hand, a general type of HE which is able to model a given stressstrain relation from very small strains to around peak as called Generall Hyperbolic Equation (GHE) has been proposed (Tatsuoka and Shibuya, 1992), which is in a simplified form: 


$$
y=\frac{x}{\frac{1}{C_{1}}+\frac{x}{C_{2}}}
$$

where

$y=\tau / \tau_{\max }$

$\tau=$ shear stress $=\left(\sigma_{1}-\sigma_{3}\right) / 2$

$\tau_{\max }=$ shear strength

$x=\gamma / \gamma_{\text {ref }}$ (normalized shear strain:

$$
\left.\gamma_{\mathrm{ref}}=\tau_{\max } / G_{\max }\right)
$$

$\gamma=$ shear strain $=\varepsilon_{1}-\varepsilon_{3}$

$G_{\max }=$ maximum shear modulus

$C_{1}=$ parameter varying with strain level

$$
\begin{aligned}
= & \frac{C_{1}(0)+C_{1}(\infty)}{2} \\
& +\frac{C_{1}(0)-C_{1}(\infty)}{2} \cos \left(\frac{\pi}{\frac{\alpha}{x}+1}\right)
\end{aligned}
$$

$C_{2}=$ parameter varying with strain level

$$
\begin{aligned}
= & \frac{C_{2}(0)+C_{2}(\infty)}{2} \\
& +\frac{C_{2}(0)-C_{2}(\infty)}{2} \cos \left(\frac{\pi}{\frac{\beta}{x}+1}\right)
\end{aligned}
$$

All the parameters $C_{1}(0), C_{2}(0), C_{1}(\infty), C_{2}(\infty)$, $\alpha$ and $\beta$ are explained in Tatsuoka and Shibuya (1992). Note that Eq. (12) ignores the initial elastic part, which is very small for normally consolidated uncemented sands, while it has been incorporated in the original form. As explained later, the $\mathrm{CHE}$ has the following form:

$$
y=\frac{x}{\frac{1}{C_{1}(\infty)}+\frac{x}{C_{2}(\infty)}}
$$

For a $\tau \sim \gamma$ relation obtained by Eq. (13), the initial shear modulus is $C_{1}(\infty) \cdot G_{\max }$ and the peak strength is $C_{2}(\infty) \cdot \tau_{\max }$. Namely, the parameters $C_{1}(\infty)$ and $C_{2}(\infty)$ are correction factors to the true values $G_{\max }$ and $\tau_{\max }$ so as to fit the CHE (Eq. 13) to a given stress-strain relation.
The analysis of the PSC test data (Tatsuoka et al., 1986) was carried out in the following four phases. In the first phase, the data were analyzed by using the CHE (Eq. 13) to determine the parameters $C_{1}(\infty)$ and $C_{2}(\infty)$. In the second phase, another data set of PSC tests of Toyoura Sand recently obtained by Park (1990) was analyzed by the GHE. He used larger specimens $(20 \mathrm{~cm}$-high, $16 \mathrm{~cm}$-long and $8 \mathrm{~cm}$-wide). He measured locally both the axial strain by means of a pair of LDTs and the lateral strain by means of eight proximity transducers (four at each side) so as to obtain strains free from $\mathrm{BE}$ for a wide range of strain from about $0.0001 \%$ to that at the peak strength state (Fig. 3). He followed the other testing conditions employed by Tatsuoka et al. (1986). The new batch of Toyoura Sand used by Park was different from the old one used by Tatsuoka et al. (1986). It has been confirmed that the physical quantities, the deformation properties and the peak strength at $\sigma_{3}$ less than $0.5 \mathrm{kgf} / \mathrm{cm}^{2}(50 \mathrm{kPa})$ are virtually the same between the old and new batches of Toyoura Sand. However, for the ordinary type of PSC tests at $\delta=90^{\circ}$ ( $\delta=$ the angle of $\sigma_{1}$-direction relative to the bedding plane), the value of $\phi$ at $\sigma_{3}$ greater than about $0.5 \mathrm{kgf} / \mathrm{cm}^{2}$ was slightly smaller for the new batch (by less than 1.5 degrees at $\sigma_{3}=0.8 \mathrm{kgf} / \mathrm{cm}^{2}$ ) than the old batch, while the deformation properties including the values of $G_{\max }$ except those near the peak are virtually the same. The new batch will be denoted as Toyoura Sand No. 2 when necessary. The GHE (Eq. 12) was fitted to this limited amount of data set obtained by Park so as to obtain the parameters which cannot be determined by using the data set by Tatsuoka et al. (1986). In the third phase, it was attempted to connect a pre-peak stress-strain relation as modelled by the GHE to a postpeak strain-softening stress-strain relation with a smooth transition at the peak stress state. And in the fourth and last phase, it was attempted to extend the GHE to use for anisotropic consolidated sands by modifying the equation defined for isotropically consolidated sands by using a simple transformation rule. 

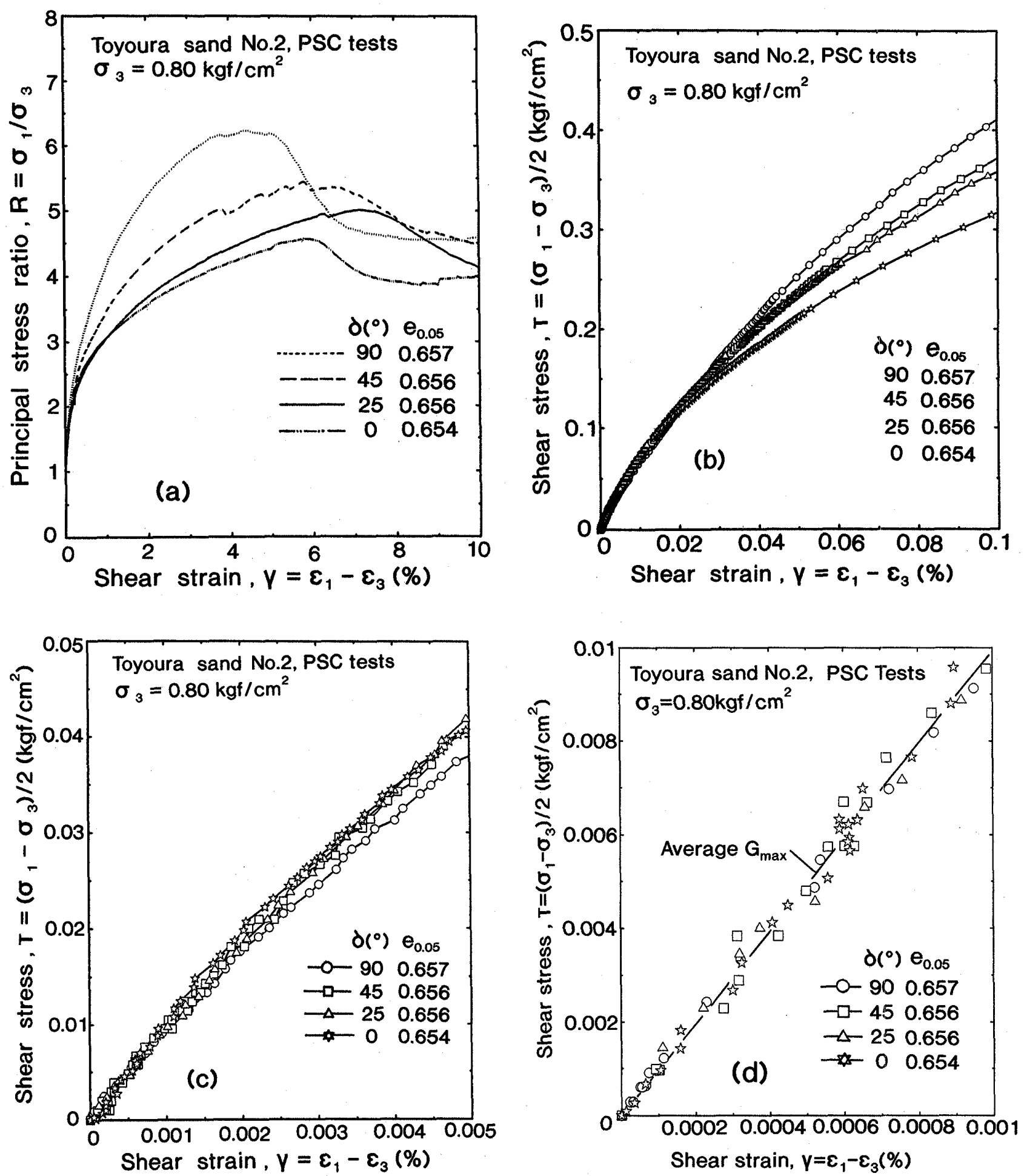

Fig. 3. Stress ratio versus shear strain relations from PSC tests on Toyoura Sand No. 2 , up to (a) $\gamma=10 \%$, (b) $\gamma=0.1 \%$ and (c) $\gamma=0.005 \%$ (d) $\gamma=0.001 \%\left(e_{0.05}:\right.$ void ratio measured at $\left.\sigma_{3}=0.05 \mathrm{kgf} / \mathrm{cm}^{2} ; 1 \mathrm{kgf} / \mathrm{cm}^{2}=98 \mathrm{kN} / \mathrm{m}^{2}\right)(P a r k$, 1990, Park and Tatsuoka, 1994)

\section{MODELLING FOR ISOTROPICALLY CONSOLIDATED SAND IN PSC}

The stress-strain relations in PSC at a constant $\sigma_{3}$ in each test of Toyoura Sand con- solidated to an isotropic stress consolidation will be modelled. This formulation considers the effects of 1) void ratio, 2) pressure level $\left(\sigma_{3}\right)$, and 3 ) the angle $\delta$ (strength and deformation anisotropy). 
From Eq. (12), we have:

$$
\frac{\tau}{\tau_{\max }}=\frac{\gamma}{\frac{\tau_{\max }}{C_{1} G_{\max }}+\frac{\gamma}{C_{2}}}
$$

For PSC at a constant $\sigma_{3}$, Eq. (14) is transformed by using $q=\sigma_{1}-\sigma_{3}=2 \tau$ to:

$$
\frac{q}{q_{\max }}=\frac{\gamma}{\frac{q_{\max }}{2 C_{1} G_{\max }}+\frac{\gamma}{C_{2}}}
$$

Dividing both the sides by $\sigma_{3}$ and rearranging by using $R=\sigma_{1} / \sigma_{3}$, we obtain:

$$
\begin{aligned}
& \frac{q}{\sigma_{3}}=\frac{\left(C_{1} 2 G_{\max } \gamma\right)\left(C_{2} q_{\max }\right)}{\sigma_{3}\left(C_{2} q_{\max }\right)+\sigma_{3}\left(C_{1} 2 G_{\max } \gamma\right)} \\
& R=1+\frac{1}{\frac{1}{A \cdot \gamma}+\frac{1}{C_{2}\left(R_{\max }-1\right)}}
\end{aligned}
$$

where

$$
\begin{aligned}
A= & \frac{C_{1} 2 G_{\max }}{\sigma_{3}} \\
= & \frac{A(0)+A(\infty)}{2}+\frac{A(0)-A(\infty)}{2} \\
& \times \cos \left(\frac{\pi}{\frac{\alpha}{x}+1}\right)
\end{aligned}
$$

The determination of the above shown parameters will be described below.

\section{Determination of the Parameters for $C_{1}$}

\section{$1.1 C_{1}(0)$ or $A(0)$}

From the nature of GHE (Eq. 12), we have:

$$
\begin{aligned}
C_{1}(0) & =A(0) \cdot \frac{\sigma_{3}}{2 G_{\max }} \\
& =\left(\frac{d R_{\text {iso }}}{d \gamma}\right)_{\gamma=0} \cdot \frac{\sigma_{3}}{2 G_{\max }} \\
& =\left(\frac{d\left(\frac{\sigma_{1}-\sigma_{3}}{2}\right)}{d\left(\varepsilon_{1}-\varepsilon_{3}\right)} \frac{1}{G_{\max }}\right)_{\gamma=0}=1.0
\end{aligned}
$$

For Toyoura Sand, an empirical equation obtained from the results of a series of resonantcolumn tests by Iwasaki and Tatsuoka (1977) and Iwasaki et al. (1978) is:

$$
G_{\max }=900 \cdot f_{e}(e) \cdot \sigma_{3}^{0.4}, \quad f_{e}(e)=\frac{(2.17-e)^{2}}{1+e}
$$

in which $G_{\max }$ and $\sigma_{3}$ are in $\mathrm{kgf} / \mathrm{cm}^{2}$. Fig. 4 shows the values of $G_{\max }$ obtained from a series of PSC tests (see Fig. 3d). As noted from Fig. 4, these values of $G_{\max }$ are only slightly less than those predicted by Eq. (20). This result indicates that the initial and maximum shear moduli determined by dynamic loading tests and those by cyclic and monotonic static loading tests are virtually the same. This point is discussed in great detail in Tatsuoka and Shibuya (1992) and Shibuya et al. $(1991,1992)$.

\section{$1.2 C_{1}(\infty)$ or $A(\infty)$}

From Eqs. 12(a) and (18), we obtain:

$$
C_{1}(\infty)=\frac{\sigma_{3} \cdot A(\infty)}{2 \cdot G_{\max }}
$$

The value of $A(\infty)$ was determined as follows. Eq. (17) can be rewritten as:

$$
\frac{\gamma}{R-1}=\frac{1}{A}+\frac{\gamma}{C_{2}\left(R_{\max }-1\right)}
$$

Eq. (22) means a linear relationship between $\gamma /(R-1)$ and $\gamma$ with the interception of $1 / A$ at the axis of $\gamma /(R-1)$. Fig. 5 shows an example of such plotting. As may be noticed, Eq. (22) does not fit the entire relation having an

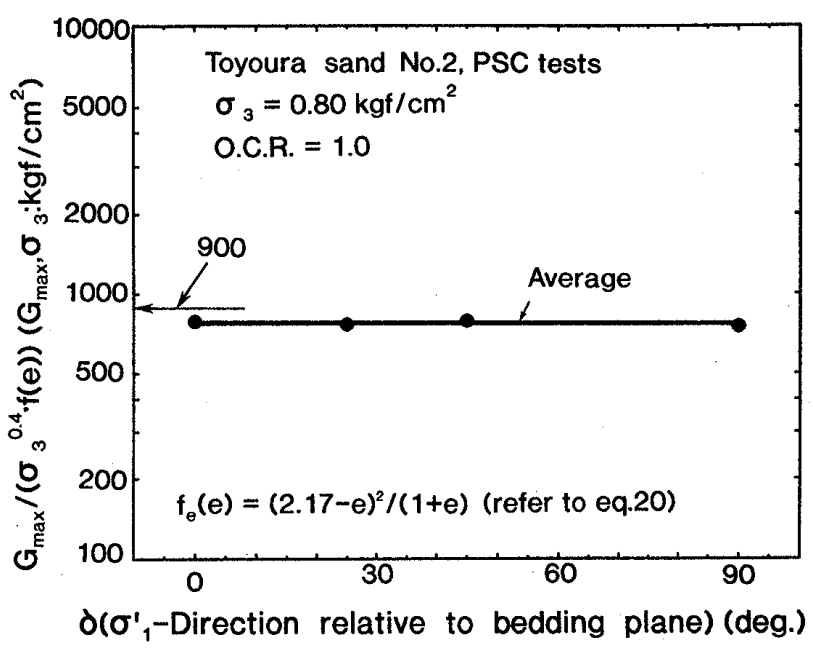

Fig. 4. Initial and maximum shear modulus plotted against $\delta$ from monotonic loading PSC tests by Park (1990) and Park and Tatsuoka (1994) 


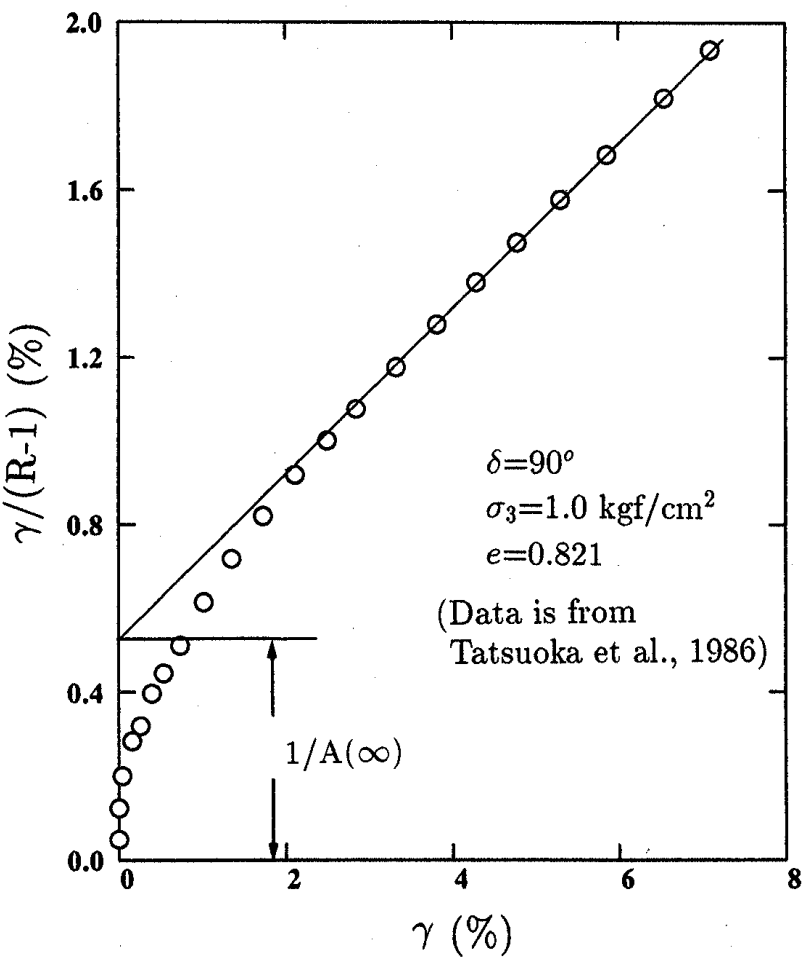

Fig. 5. Typical conventional hyperbolic equation fitting for PSC test data $\left(R=\sigma_{1} / \sigma_{3}\right)$

upwards-concaved tendency. In this study, a linear relation was fitted to the part at relatively large strain levels of stress-strain relation to obtain the value of $A(\infty)$ (Fig. 5). This fitting method was first proposed by Kondner (1963) and since then, many researchers (e.g., Duncan and Chan, 1970) have used it. Therefore, this fitting method is called herein the conventional hyperbolic fitting (CHF).

Since the parameter $A(\infty)$ is a function of $\delta$, $e$ and $\sigma_{3}$, it was assumed to be modelled by:

$$
A(\infty)=A_{1}\left(\sigma_{3}\right) \cdot f_{1}(e) \cdot g_{1}(\delta)
$$

in which $f_{1}(e=0.7)=1.0$ and $g_{1}\left(\delta=90^{\circ}\right)=1.0$, and therefore, $A_{1}\left(\sigma_{3}\right)$ is the value of $A(\infty)$ when $e=0.70$ and $\delta=90^{\circ}$ (herein, the void ratio $e$ means the value $e_{0.05}$ measured at $\sigma_{3}=0.05 \mathrm{kgf} / \mathrm{cm}^{2}$ ). These two specific values were selected since the largest number of data was available at and near these conditions. At each $\sigma_{3}$, the value of $A_{1}\left(\sigma_{3}\right)$ was obtained by interpolating the relationship at $\delta=90^{\circ}$ between $A(\infty)$ and $e$ to $e=0.70$. The result is plotted in Fig. 6. From this plot, the function $A_{1}\left(\sigma_{3}\right)$ was determined by the 2 nd degree regression in

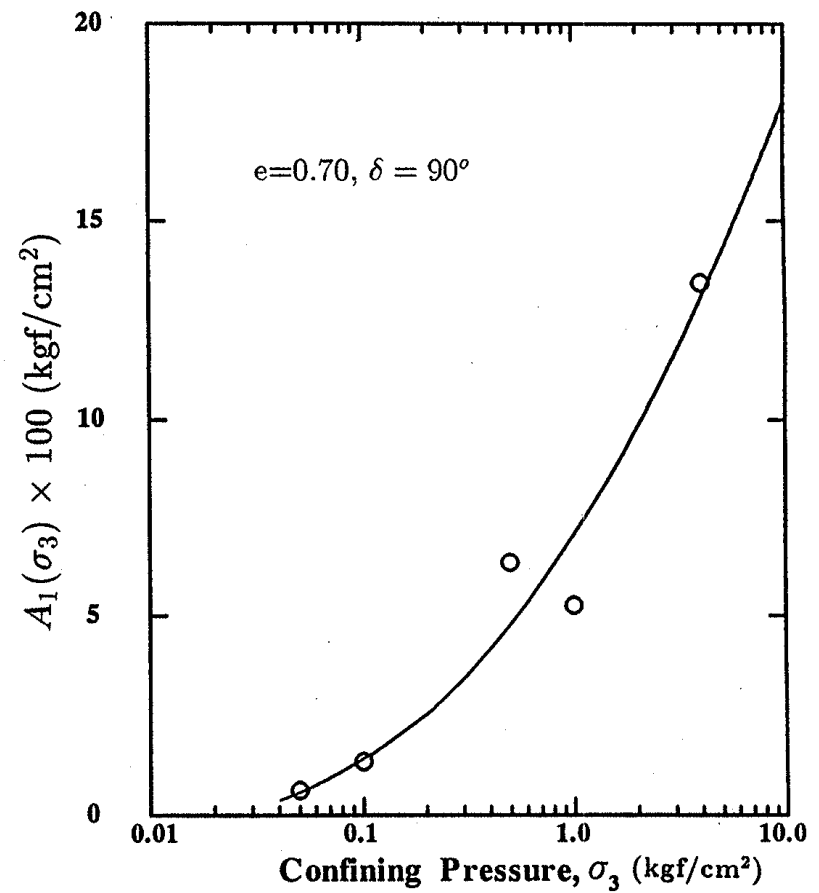

Fig. 6. $A_{1}\left(\sigma_{3}\right)=A\left(e=0.70, \delta=90^{\circ}\right)$ plotted against $\sigma_{3}$ (based on the data by Tatsuoka et al., 1986)

semilog scale as:

$$
A_{1}\left(\sigma_{3}\right)=704+833 \cdot \log \left(\sigma_{3}\right)+268 \cdot\left\{\log \left(\sigma_{3}\right)\right\}^{2}
$$

in which $A_{1}\left(\sigma_{3}\right)$ and $\sigma_{3}$ are in $\mathrm{kgf} / \mathrm{cm}^{2}$. Note that for $\mathrm{A}$ in Eq. (22), thus for $A_{1}\left(\sigma_{3}\right)$ in Eq. (24), $\gamma$ is in decimal. Note also that a half of the first term $704\left(\mathrm{kgf} / \mathrm{cm}^{2}\right)$ means the maximum shear modulus $G_{\max }$ at $e=0.7$ and $\sigma_{3}=1.0 \mathrm{kgf} / \mathrm{cm}^{2}$ estimated by the CHF. This value is only about $30 \%$ of the measured initial shear modulus $G_{\max }$ at small strain levels (see Figs. 3(c) and 4). Accordingly, if the GHE (Eq. 12) is used, as strain increases from zero to very large values, $C_{1}$ decreases from $C_{1}(0)$ $=1.0($ Eq. 19$)$ to $C_{1}(\infty)$, which is about 0.3.

Next, for each value of $\sigma_{3}$ examined, the ratio of " $A(\infty)$ at $\delta=90^{\circ}$ and a void ratio $e$ " to " $A_{1}\left(\sigma_{3}\right)$ obtained by substituting the value of $\sigma_{3}$ into Eq. (24)" was obtained and plotted against $e$ in Fig. 7. Referring to Eq. (23), this ratio is $f_{1}(e)$. A large scatter in the experimental data is due primarily to the scattering data points at very low pressure levels. Considering that a well defined relationship can be seen for $\sigma_{3}=1.0$ and $4.0 \mathrm{kgf} / \mathrm{cm}^{2}$ (98 and $392 \mathrm{kPa}$ ), the 


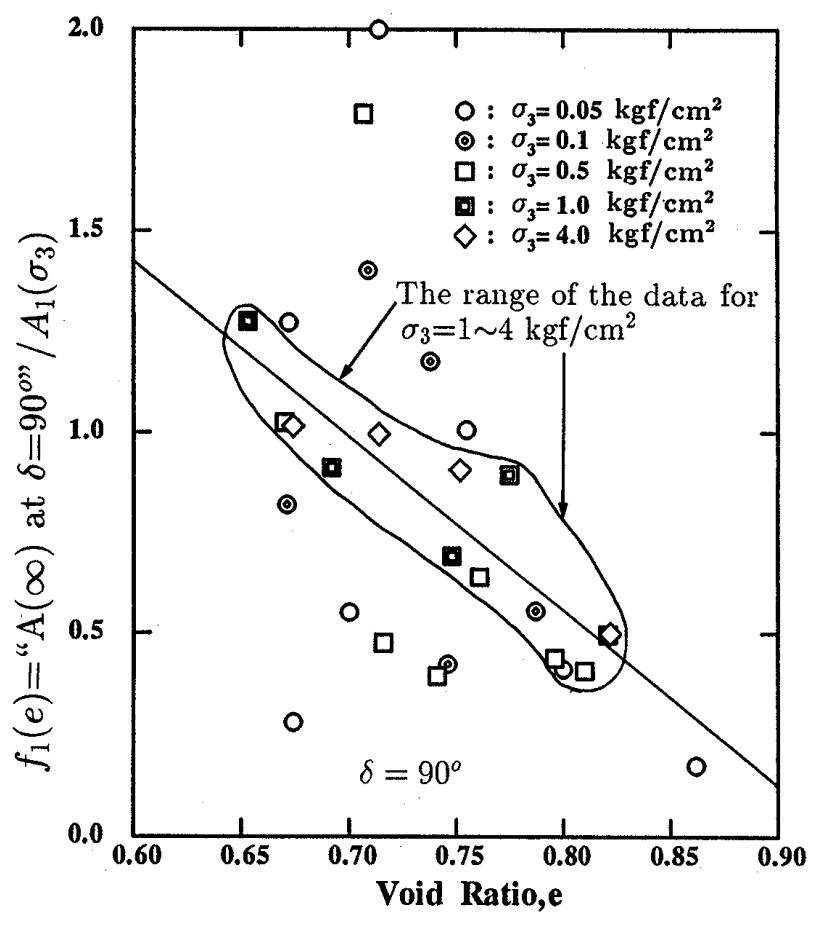

Fig. 7. Linear regression of the relationship between $f_{1}(e)=" A(\infty)$ at $\delta=90^{\circ} " / A_{1}\left(\sigma_{3}\right)$ and void ratio, $e$

best fit linear regression line as shown in Fig. 7 was obtained:

$$
f_{1}(e)=1.0+4.342(0.7-e)
$$

Then, also each value of $\sigma_{3}$ examined, the ratio of " $A(\infty)$ at a certain value of $\delta$ " to " $A_{1}\left(\sigma_{3}\right)$ obtained by substituting the value of $\sigma_{3}$ into Eq. (24)" (both of which are the values at $e=0.7$ ) was obtained and plotted against $\delta$ in Fig. 8. Again referring to Eq. (23), this ratio is $g_{1}(\delta)$. It may be seen that the stiffness parameter $A(\infty)$ decreases as $\delta$ decreases due to the inherent anisotropy of the sand. Again, since the scattering was too large to define different relations for different values of $\sigma_{3}$, the average value for each $\delta$ was obtained. Neglecting one data point at $\delta=67^{\circ}$, the function $g_{1}(\delta)$ for the range $\delta>45^{\circ}$ was obtained by the regression analysis under the conditions; $g_{1}\left(\delta=90^{\circ}\right)=1.0$ and the derivative $d g_{1}(\delta) / d \delta=0$ at $\delta=90^{\circ}$ (note that $\delta$ is in degree):

$$
g_{1}(\delta)=0.281+1.44 \cdot(\delta / 90)-0.72 \cdot(\delta / 90)^{2}
$$

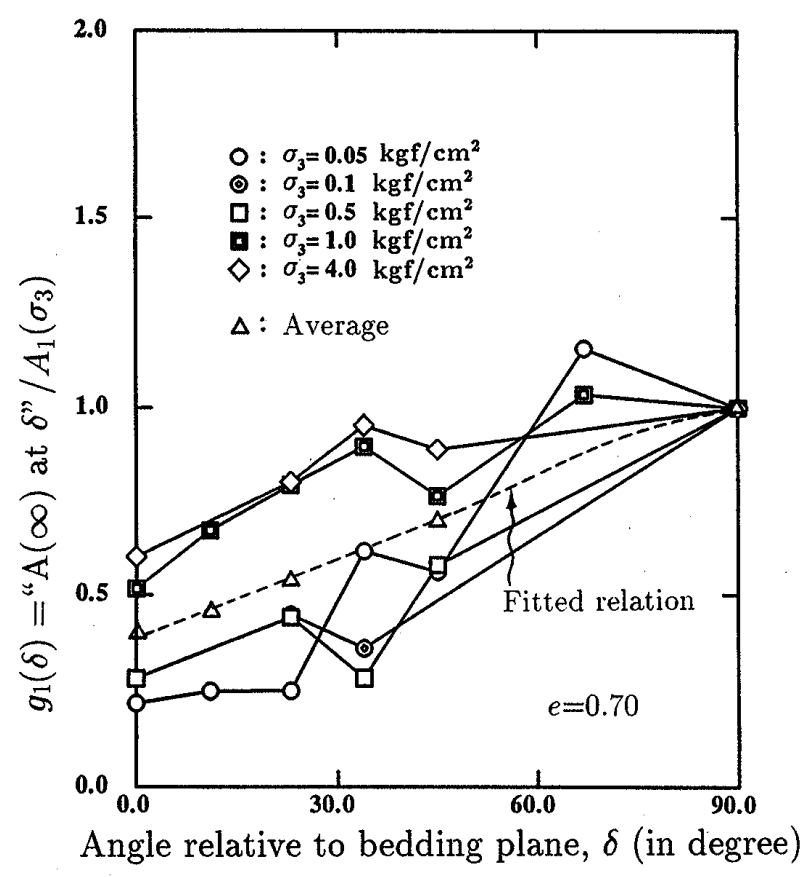

Fig. 8. Relationship between $g_{1}(\delta)=" A(\infty)$ at $\delta " / A_{1}\left(\sigma_{3}\right)$ and $\delta$, when $e=0.70$

And $g_{1}(\delta)$ for the other half range $\delta<45^{\circ}$ was regressed linearly as:

$$
g_{1}(\delta)=0.396+0.594 \cdot(\delta / 90)
$$

\section{$1.3 \alpha$}

This constant $\alpha$ helps in fitting Eq. (12) to a given data which has a high degree of nonlinearity around $x=1\left(x=\gamma / \gamma_{r}, \gamma_{r}=\tau_{\max } /\right.$ $\left.G_{\max }, \gamma=\varepsilon_{1}-\varepsilon_{3}\right)$. The values of $\alpha$ were determined from a limited amount of data of PSC tests performed by Park (1990) as follows. Fig. 9 shows the result of fitting of the GHE (Eq. 12) to a typical stress-strain relation in the normalized form, obtained from a PSC test at $e=0.654, \quad \sigma_{3}=0.8 \mathrm{kgf} / \mathrm{cm}^{2}$ and $\delta=0.0^{\circ}$. Note that $y=\tau / \tau_{\max }\left(\tau=\left(\sigma_{1}-\sigma_{3}\right) / 2\right)$, and $\tau_{\max }$ and $G_{\max }$ are the measured values. The parameters used in Eq. (12) were obtained as follows (Tatsuoka and Shibuya, 1992). First, $C_{1}(0)=1.0$ (Eq. 19). Referring to Fig. 9(c), $C_{2}(0)$ is the intercept at the y axis of the linear relation starting from the starting point ( $y=0$, $y / x=1)$, fitted to the initial part of the observed relation. Further, the parameters $C_{1}(\infty)$ and $C_{2}(\infty)$ are the intercepts at the $y / x$ axis and the $y$ axis, respectively, of the linear relation fitted to the observed stress-strain rela- 

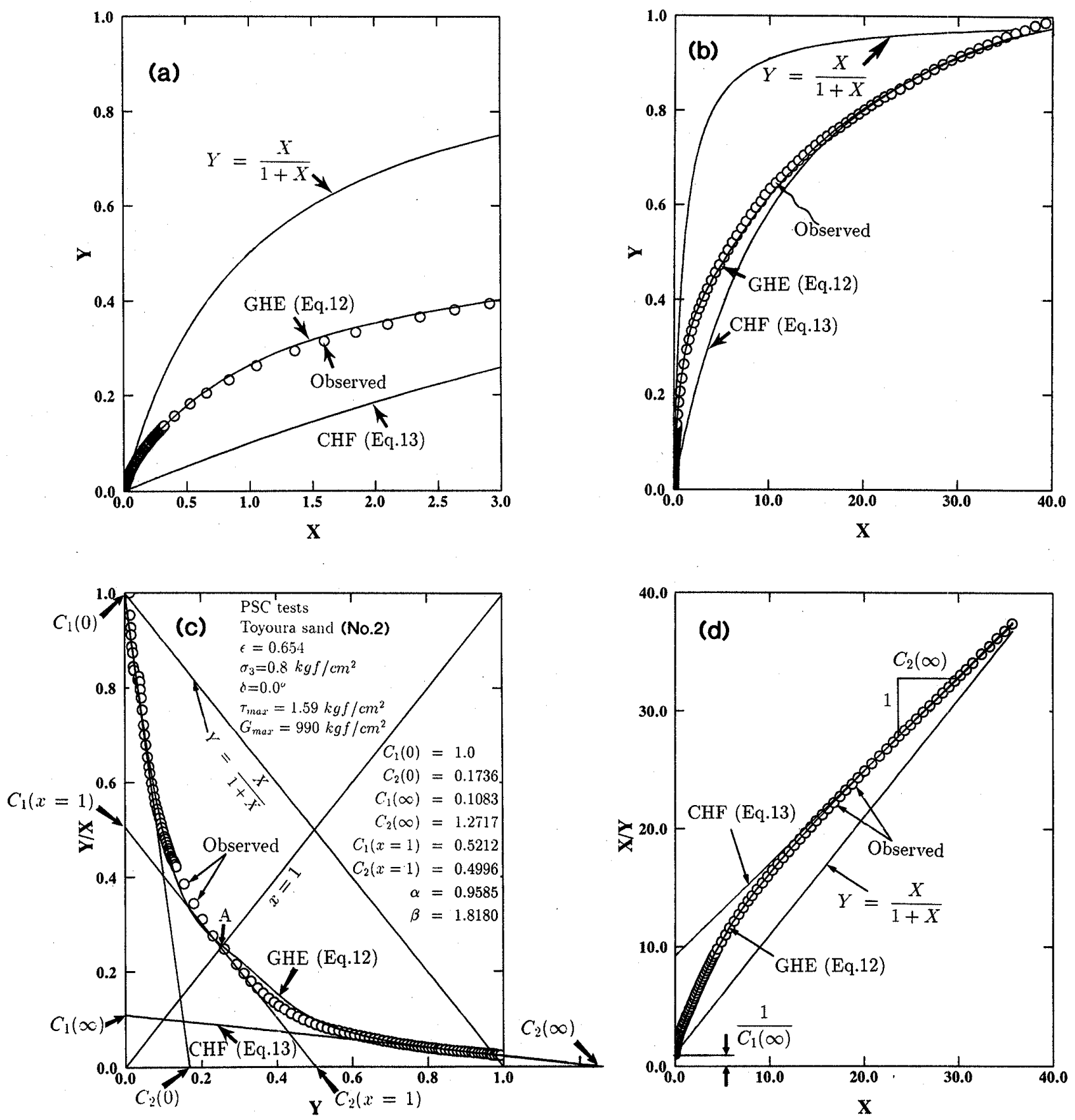

Fig. 9. Fitting of hyperbolic relations to a typical stress-strain relation in PSC obtained by Park $(1990)(e=0.654$, $\left.\sigma_{3}=0.8 \mathrm{kgf} / \mathrm{cm}^{2}, \delta=0.0^{\circ}\right)$

tion at large strains. Actually, these values of $C_{1}(\infty)$ and $C_{2}(\infty)$ were obtained by linear fitting to the $X / Y \sim X$ relation (Fig. 9d), which is similar to that shown in Fig. 5. Eq. (13) using these values of $C_{1}(\infty)$ and $C_{2}(\infty)$ is denoted as the conventional hyperbolic fitting (CHF) in Fig. 9. It may be seen that the CHF can model the measured relation only at large strains, but cannot utterly at small strains. In
Fig. 9(c), at Point A, the diagonal implying the relation $x=1$ intersects with the observed relation. A line which is drawn tangent to the observed relation at Point $\mathrm{A}$ intersects with the $y / x$ axis at $C_{1}(x=1)$ and with the $y$ axis at $C_{2}(x=1)$. The values of $\alpha$ and $\beta$ are obtained by substituting these values together with known values of $C_{1}(0)=1.0, C_{1}(\infty), C_{2}(0)$, $C_{2}(\infty)$ and $x=1$ into Eqs. 12(a) and (b). In 
Fig. 9, Eq. (12) using the parameters determined by the above-mentioned method denoted as the GHE. It may be seen that this GHE fits very satisfactorily the observed relation from very small to large strains. Note that the relation $y=x /(1+x)$ means Eq. (13) using $C_{1}(\infty)=C_{2}(\infty)=1.0$, which is obtained without any fitting procedure as shown in Figs. 9(c) and (d). It is seen that this relation overestimates largely the observed stiffness for the entire strain range except at the very beginning stage. A more detailed discussion on this point is given in Tatsuoka and Shibuya (1992).

The following relation was assumed for the parameter $\alpha$ :

$$
\alpha=f\left(\sigma_{3}, \delta\right)=\alpha_{90}\left(\sigma_{3}\right) * g_{\alpha}(\delta)
$$

where $\alpha_{90}\left(\sigma_{3}\right)$ is the value of $\alpha$ at $\delta=90^{\circ}$ and $g_{\alpha}(\delta)$ is the ratio of $\alpha$ at a certain value of $\delta$ to $\alpha_{90}$. Fig. 10 shows the values $\alpha_{90}$ plotted against $\sigma_{3}$ and the fitted curve for it. On the other hand, only at $\sigma_{3}=0.8 \mathrm{kgf} / \mathrm{cm}^{2}$, the data for the entire range of $\delta$ from $90^{\circ}$ to $0^{\circ}$ were available. By using these data, therefore, the values of $g_{\alpha}(\delta)$ were obtained as plotted

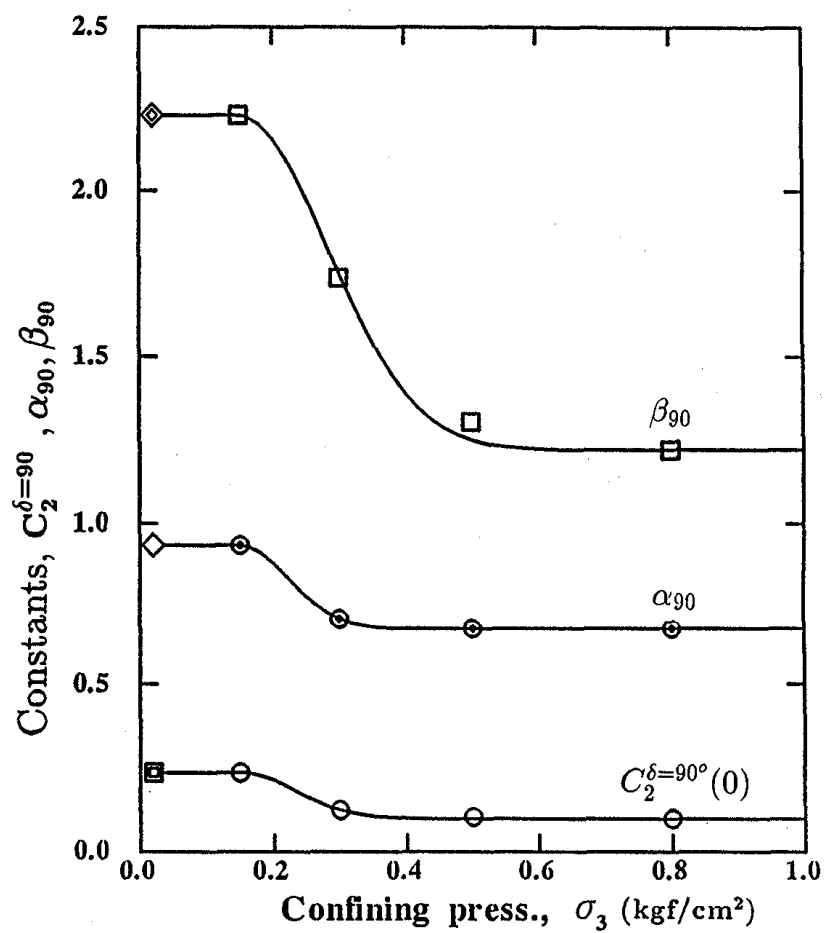

Fig. 10. Variation of three GHE parameters $(\alpha, \beta$, $C_{2}(0)$ ) with confining pressures $\left(\sigma_{3}\right)$ obtained from the data of the PSC tests performed by Park (1990) against $\delta=90^{\circ}$ as shown in Fig. 11, and a linear relation was fitted to them. Based on these analyses the following empirical relations were obtained:

$$
\begin{aligned}
& \alpha_{90}=0.673+0.262 \exp \left(-\left(\frac{\sigma_{3}-0.15}{0.102}\right)^{2}\right) \\
& \qquad \text { for } \sigma_{3} \geq 0.15 \mathrm{kgf} / \mathrm{cm}^{2} \\
& \alpha_{90}=0.935 \text { for } \sigma_{3}<0.15 \mathrm{kgf} / \mathrm{cm}^{2} \\
& g_{\alpha}(\delta)=1.690-0.690 \cdot(\delta / 90)
\end{aligned}
$$

\section{Determination of the Parameters for $C_{2}$}

When Eq. (13) is used, the parameter $C_{2}$ is constant with respect to strain, equal to $C_{2}(\infty)$. In the GHE formulation, however, it varies for the entire strain range in order to have a satisfactory fitting to a given experimental data. Referring to Eq. 12(b), this parameter $C_{2}$ involves three constants $\left(C_{2}(0), C_{2}(\infty)\right.$ and $\left.\beta\right)$, which are to be determined accurately.

\section{$2.1 \quad C_{2}(0)$}

From a limited number of the PSC test data obtained by Park (1990), this parameter was obtained as shown in Figs. 10 and 11, and

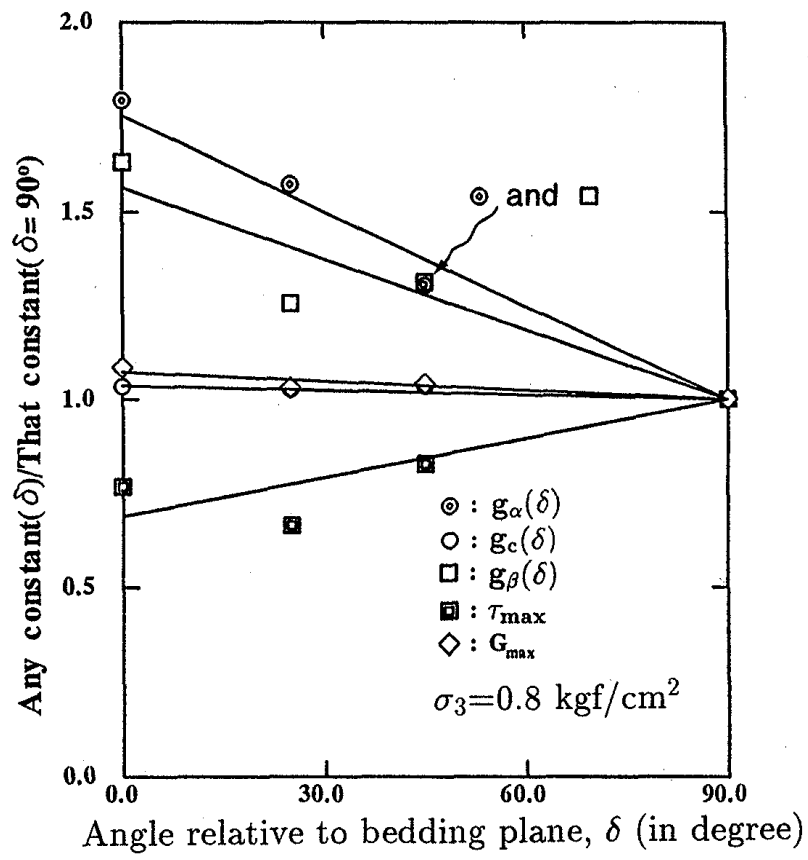

Fig. 11. Variation of three GHE parameters $(\alpha, \beta$, $\left.C_{2}(0)\right)$ with the bedding plane orientation, $\delta$, obtained from the data of the PSC tests performed by Park (1990) $\left(1.0 \mathrm{kgf} / \mathrm{cm}^{2}=98 \mathrm{kPa}\right)$ 
fitted as follows:

$$
C_{2}(0)=C_{2}^{\delta=90} * g_{c}(\delta)
$$

where

$$
\begin{aligned}
& C_{2}^{\delta=90}=0.10+0.136 * \exp \left(-\left(\frac{\sigma_{3}-0.15}{0.116}\right)^{2}\right) \\
& \quad \text { for } \sigma_{3} \geq 0.15 \mathrm{kgf} / \mathrm{cm}^{2} \\
& C_{2}^{\delta=90}=0.236 \quad \text { for } \sigma_{3}<0.15 \mathrm{kgf} / \mathrm{cm}^{2} \\
& g_{c}(\delta)=1.0428-0.0428 \cdot(\delta / 90)
\end{aligned}
$$

\section{$2.2 \quad C_{2}(\infty)$}

This parameter was determined from the following analysis of the PSC data obtained by Tatsuoka et al. (1986). At the best, a hyperbolic equation can be fitted to a given stressstrain relation up to the peak stress state. The parameter $C_{2}(\infty)$ was determined based on Eq. (22) as $C_{1}(\infty)$ (Fig. 9(d)). This parameter also was assumed to be a function of $\delta, e$ and $\sigma_{3}$ as $C_{1}(\infty)$, and was modelled by:

$$
C_{2}(\infty)=A_{2}\left(\sigma_{3}\right) \cdot f_{2}(e) \cdot g_{2}(\delta)
$$

in which $f_{2}(e=0.70)=1.0$ and $g_{2}\left(\delta=90^{\circ}\right)$

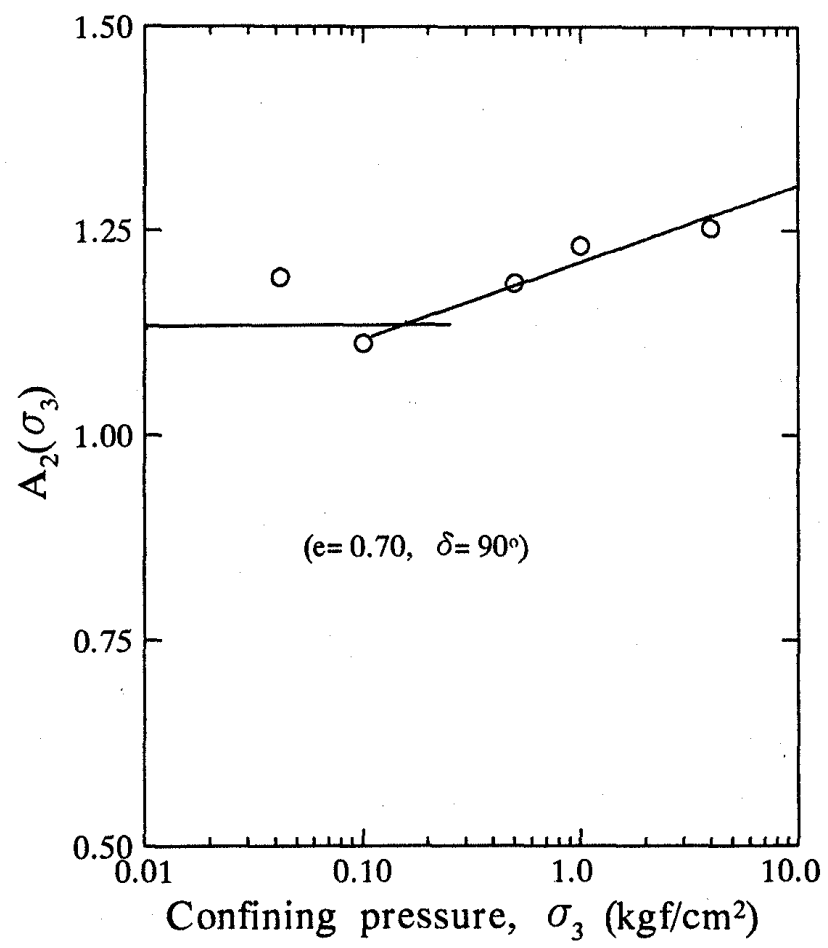

Fig. 12. Linear regression of the relationship between $A_{2}\left(\sigma_{3}\right)=C_{2}(\infty) \quad\left(e=0.70, \delta=90^{\circ}\right)$ and confining pressure, $\sigma_{3}$
=1.0, and therefore $A_{2}\left(\sigma_{3}\right)$ is the value of $C_{2}(\infty)$ when $e=0.70$ and $\delta=90^{\circ}$. Following the same procedure for defining $A_{1}(\infty)$, the value of $A_{2}\left(\sigma_{3}\right)=$ " $C_{2}(\infty)$ at $e=0.70$ and $\delta=90^{\circ}$ " was obtained for each $\sigma_{3}$ and was shown in Fig. 12. The regressed relations are: $A_{2}\left(\sigma_{3}\right)=1.212+0.093 \cdot \log \left(\sigma_{3}\right)$

$$
\text { for } \sigma_{3} \geq 0.15 \mathrm{kgf} / \mathrm{cm}^{2}
$$

$A_{2}\left(\sigma_{3}\right)=1.135$ for $\sigma_{3}<0.15 \mathrm{kgf} / \mathrm{cm}^{2}$

From the observation of Figs. 13 and 14, it can be assumed that $f_{2}(e)=g_{2}(\delta)=1.0$. Namely, $C_{2}(\infty)$ can be assumed to be a function of only $\sigma_{3}$.

$2.3 \beta$

The parameter $\beta$ was determined as the parameter $\alpha$ by using the limited number of test data by Park (1990) as shown in Figs. 10 and 11, which are:

$$
\beta=f\left(\sigma_{3}, \delta\right)=\beta_{90}\left(\sigma_{3}\right) \cdot g_{\beta}(\delta)
$$

where,

$$
\begin{array}{r}
\beta_{90}=1.219+1.012 \exp \left\{-\left(\frac{\sigma_{3}-0.15}{0.188}\right)^{2}\right\} \\
\sigma_{3} \geq 0.15 \mathrm{kgf} / \mathrm{cm}^{2}
\end{array}
$$

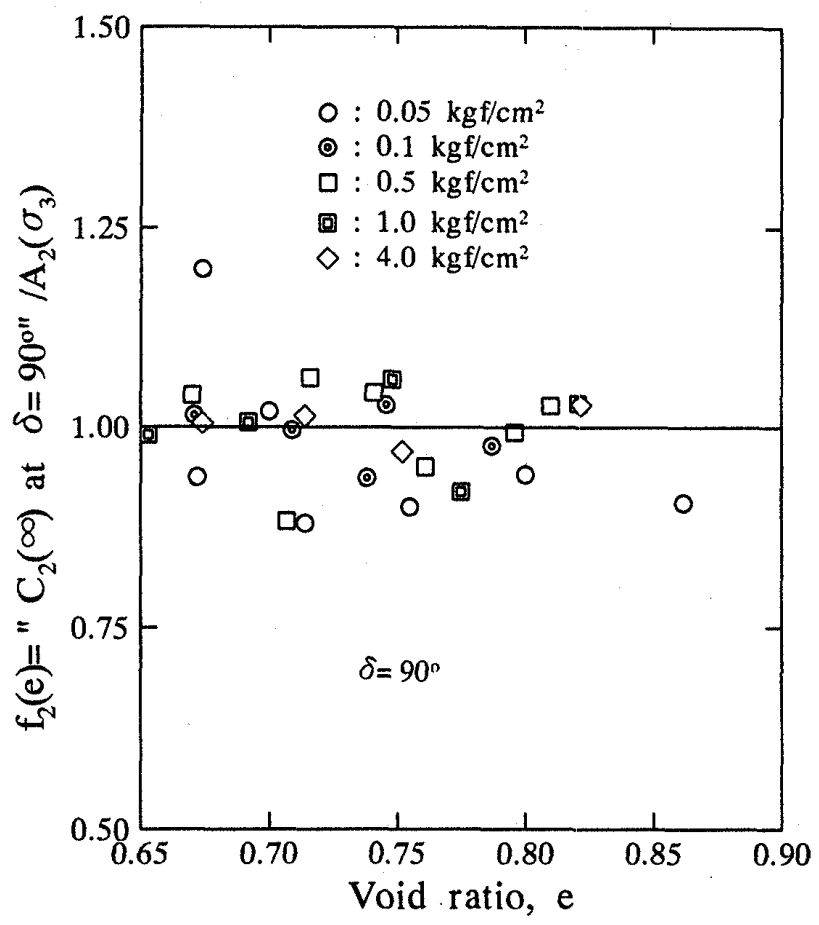

Fig. 13. Linear regression of the relationship between $f_{2}(e)=" C_{2}(\infty)$ at $\delta=90^{\circ} " / A_{2}\left(\sigma_{3}\right)$ and void ratio, $e$ 


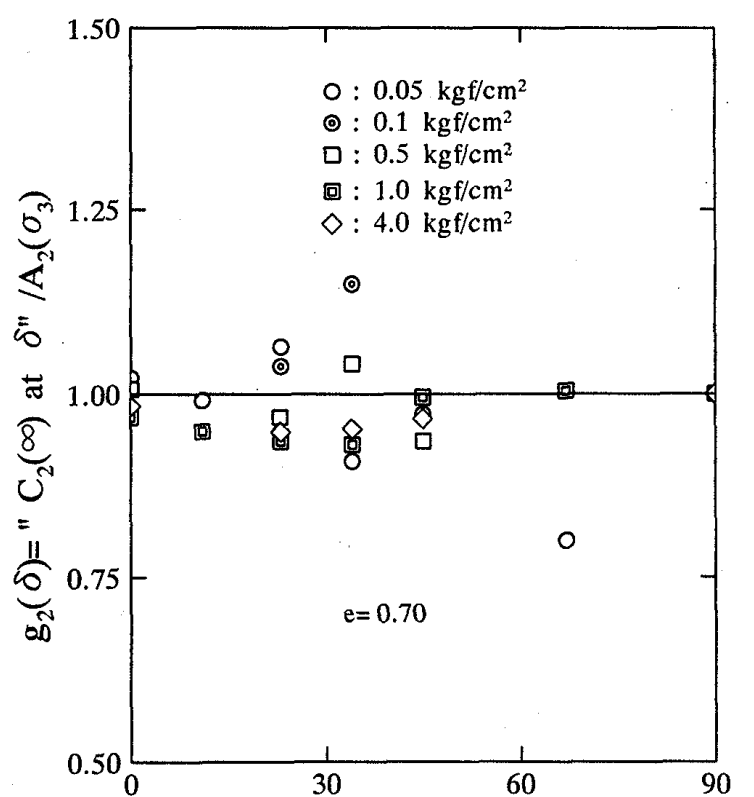

Angle relative to bedding plane, $\delta$ (in degree)

Fig. 14. Linear regression of the relationship between $g_{2}(\delta)=$ " $C_{2}(e)$ at $\delta " / A_{2}\left(\sigma_{3}\right)$ and $\delta$

$\beta_{90}=2.231 \sigma_{3}<0.15 \mathrm{kgf} / \mathrm{cm}^{2}$

$g_{\beta}(\delta)=1.508-0.0508 \cdot(\delta / 90)$

\section{MODELLING NEAR AND AT PEAK}

The hyperbolic relation is not flat (i.e., $d \tau(d \gamma \neq 0)$ at the peak state at a limited value of strain. So it is needed to introduce some modification to alleviate this drawback. One way is to modify the hyperbolic equation so as to have a zero tangent at the peak stress state (Prevost and Keane, 1989). In their method, however, the pre-peak relation loses flexibility in fitting to a given stress-strain relation. Therefore, another method was introduced as described below. The final equation $R(\gamma)$ used to fit an arbitrarily chosen small range up to the peak stress state of a given pre-peak stressstrain relation is given as (Fig. 15):

$$
R(\gamma)=F(\gamma)+G(\gamma)
$$

where,

$$
\begin{aligned}
& F(\gamma)=p(\gamma) \cdot f(\gamma) \\
& G(\gamma)=[1-p(\gamma)] \cdot g(\gamma)
\end{aligned}
$$

where $f(\gamma)$ is a fitted generalized hyperbolic

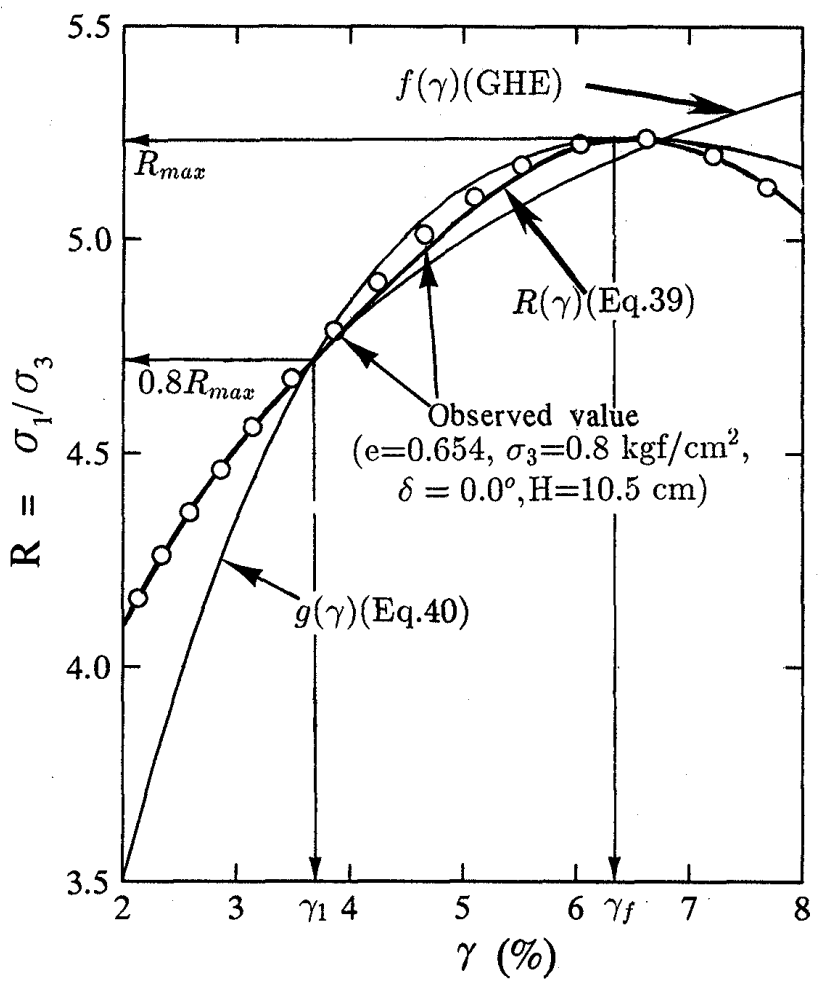

Fig. 15. Fitting near and at the peak stress state

equation (GHE), $g(\gamma)$ is a function which has a zero tangent modulus at the peak, and $p(\gamma)$ is the connecting function, which is 1.0 at $\gamma=0$ and 0.0 at $\gamma=\gamma_{f}$ (shear strain at the peak state). As the function $g(\gamma)$, Eq. (40) proposed by Tanaka et al. (1988) was used. This equation passes through two definite points on the $g(\gamma)$ $\sim \gamma$ relation; $(\gamma=0, g=1)$ and $\left(\gamma=\gamma_{f}, g=R_{\max }\right)$ :

$$
g(\gamma)=\left(R_{\max }-1.0\right) \cdot\left(\frac{2.0 \sqrt{\gamma \cdot \gamma_{f}}}{\gamma+\gamma_{f}}\right)^{s}+1.0
$$

where $R_{\max }=\left(\sigma_{1} / \sigma_{3}\right)_{\max }$. The power $s$ will be explained later. When the accurate values of $\gamma_{f}$ and $R_{\max }$ are used, Eq. (40) (therefore, Eq. 39) passes through the measured peak point for a given data. Note that the GHE, $f(\gamma)$, does not necessarily pass through the measured peak point even when the parameters are given by using the fitted equations presented so far. Then, first the measured values of $\gamma_{f}$ and $R_{\max }$ were formulated as functions of $e, \sigma_{3}$ and $\delta$ as follows.

1. $\gamma_{f}$

Since the amount of the data was largest for $\delta=90^{\circ}$ and the model bearing capacity tests 
were performed mainly for dense deposits with void ratios less than about $0.7, \gamma_{f}$ was modeled as:

$$
\gamma_{f}=\gamma_{f 1}\left(\sigma_{3}\right) \cdot f_{\gamma}(e) \cdot g_{\gamma}(\delta)
$$

where $\gamma_{f 1}\left(\sigma_{3}\right)$ is $\gamma_{f}$ when $e=0.7$ and $\delta=90^{\circ}$, and $f_{\gamma}(e=0.70)=g_{\gamma}\left(\delta=90^{\circ}\right)=1.0$. At each $\sigma_{3}$, the relationship between $\gamma_{f}\left(e, \delta=90^{\circ}\right)$ and $e$ was plotted and from that, the value of $\gamma_{f 1}$ was obtained. Then the value of $\gamma_{f 1}$ was plotted against $\sigma_{3}$ in $\mathrm{kgf} / \mathrm{cm}^{2}$ (Fig, 16), and fitted by the following two relations:

For $\sigma_{3} \leq 0.5 \mathrm{kgf} / \mathrm{cm}^{2}$,

$$
\gamma_{f 1}=3.75(\%)
$$

For $\sigma_{3}>0.5 \mathrm{kgf} / \mathrm{cm}^{2}$,

$$
\gamma_{f 1}=5.05+4.165 \log \left(\sigma_{3}\right)(\%)
$$

These equations were determined so as to be as simple as possible, considering the limited amount of data. More data are required to refine them. The function $f_{\gamma}(e)$ was obtained from the plotting of the ratio of $\gamma_{f}\left(e, \delta=90^{\circ}\right)$ to " $\gamma_{f}\left(e=0.70, \delta=90^{\circ}\right)\left(=\gamma_{f 1}\right)$ obtained from Eq. (42)" against the void ratio $e$ (Fig. 17). The scatter is large only in the data at

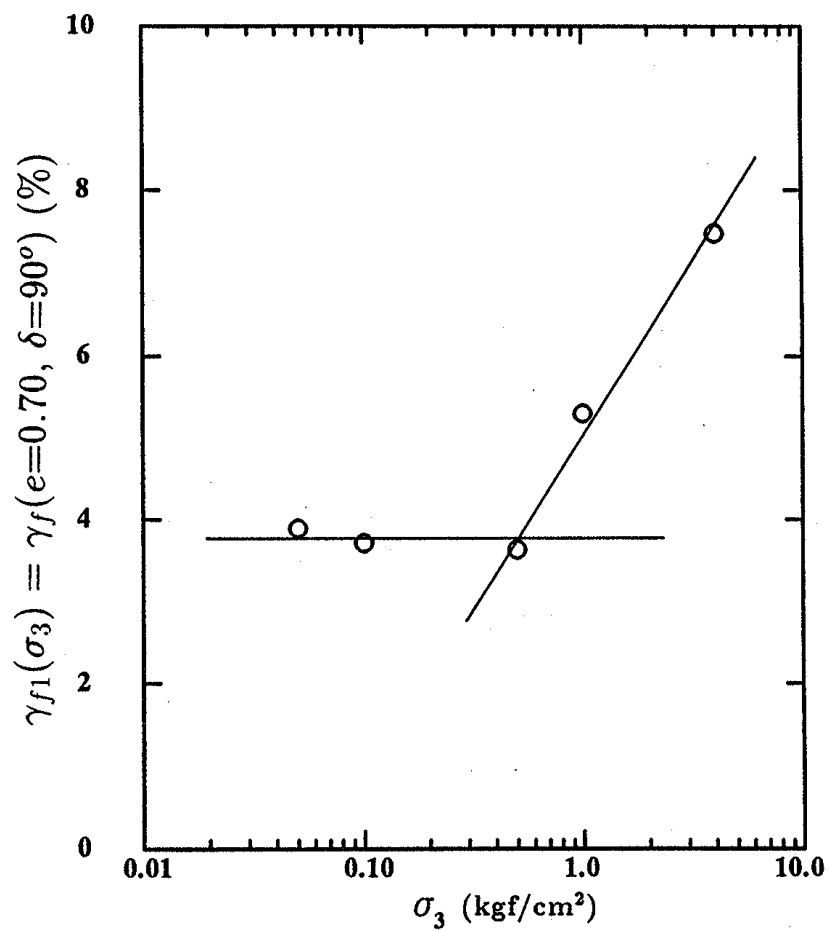

Fig. 16. Bilinear regression of the relationship between $\gamma_{f 1}\left(\sigma_{3}\right)=\gamma_{f}\left(e=0.70, \delta=90^{\circ}\right)$ and $\sigma_{3}$

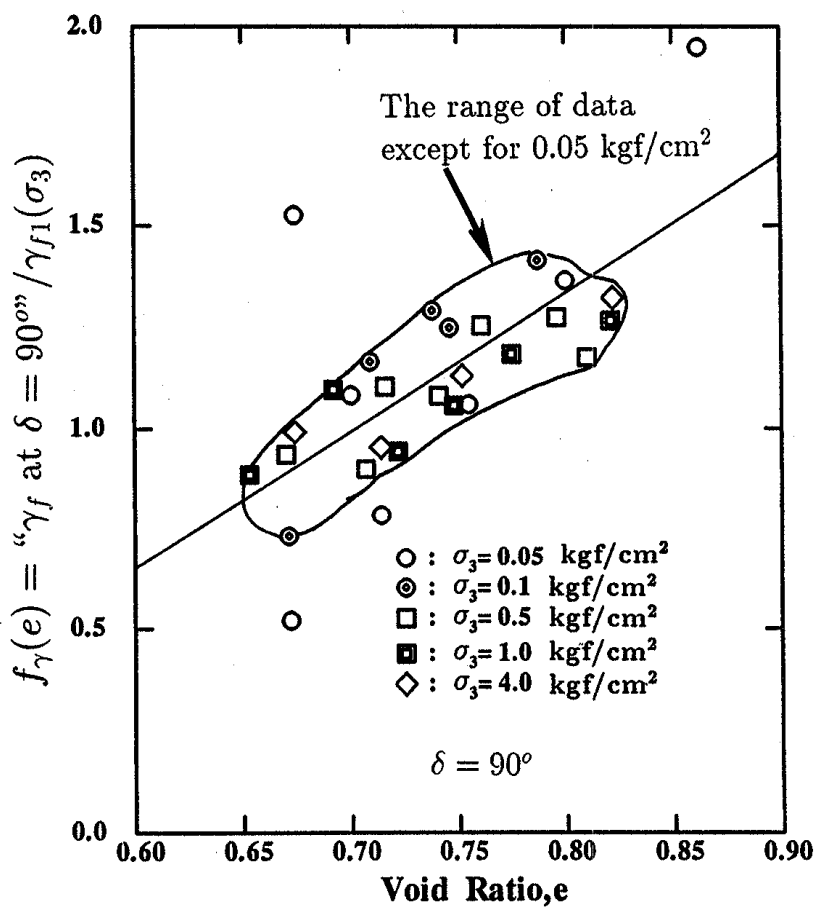

Fig. 17. Linear regression of the relationship of " $\gamma_{f}$ at $\delta=90^{\circ} " / \gamma_{f}\left(e=0.70, \delta=90^{\circ}\right)\left(=\gamma_{f 1}\right)$ and $e$

$\sigma_{3}=0.05 \mathrm{kgf} / \mathrm{cm}^{2}(4.9 \mathrm{kPa})$. The best fit regression line is:

$$
f_{\gamma}(e)=1.0+3.42(e-0.7)
$$

In order to define $g_{\gamma}(\delta)$, the ratios of $\gamma_{f}(e=0.7, \delta)$ to " $\gamma_{f}\left(e=0.7, \delta=90^{\circ}\right)=\gamma_{f 1}$ by Eq. (42)" were plotted against $\delta$ separately for each $\sigma_{3}$ (Fig. 18). The general trend seen is that $\gamma_{f}$ increases as $\delta$ decreases. This is due to the inherently anisotropic fabric of air-pluviated Toyoura Sand. Since the scatter of the data was found too large to define different functions $g_{\gamma}(\delta)$ for different values of $\sigma_{3}$, the values at the same $\delta$ were averaged as shown in Fig. 18. Then, the function $g_{\gamma}(\delta)$ was determined neglecting the most deviating data point at $\delta=67^{\circ}$ so that $g_{\gamma}(\delta)$ simply increases as $\delta$ decreases and the derivative $d g_{\gamma}(\delta)$ $/ d \delta=0$ at $\delta=90^{\circ}$ as:

$$
g_{\gamma}(\delta)=1.668-1.336 \cdot(\delta / 90)+0.668 \cdot(\delta / 90)^{2}
$$

\section{2. $R_{\max }$}

$R_{\max }$ is the measured peak value of $R\left(=\sigma_{1} / \sigma_{3}\right)$ : 


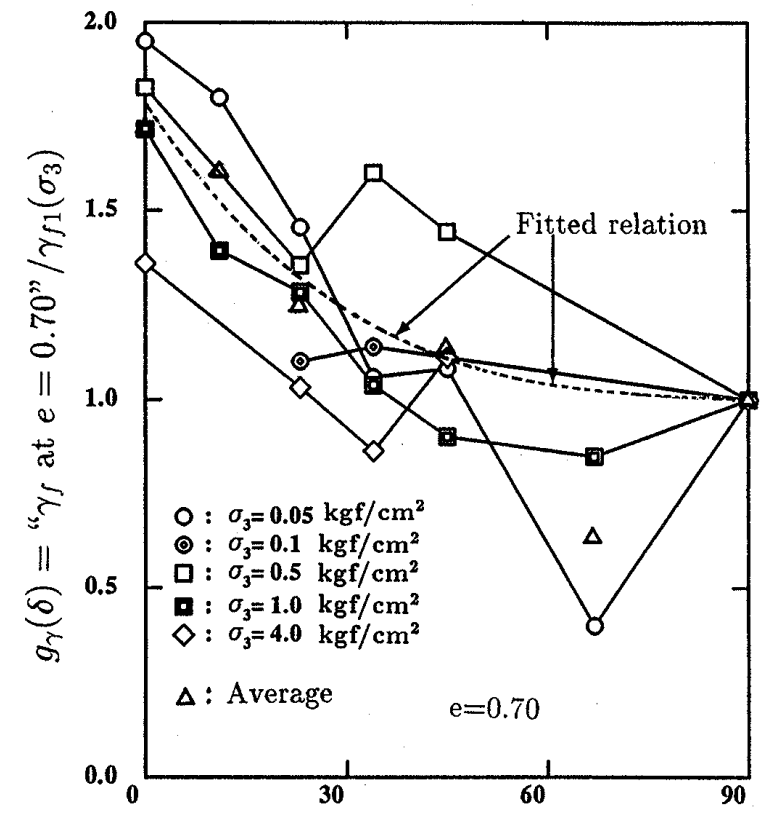

Angle relative to bedding plane, $\delta$ (in degree)

Fig. 18. Regression of the relationship between " $y_{f}$ at $\boldsymbol{e}=\mathbf{0 . 7 0} " / \gamma_{f 1}$ and $\delta$

$$
R_{\max }=\frac{1+\sin \phi}{1-\sin \phi}
$$

where $\phi$ is the angle of internal friction as functions of $e, \delta$ and $\sigma_{3}$. Based on the PSC test data reported by Tatsuoka et al. (1986) and Tatsuoka (1987), the following empirical equation was obtained:

$$
\begin{aligned}
\phi(\text { in degree })= & \{59.47 \cdot(1.5-e)-10 \cdot(1-e) \\
& \left.\cdot \log _{10}\left\{\sigma_{3} /\left(\sigma_{3}\right)_{0}\right\}\right\} \cdot g_{R}(\delta)
\end{aligned}
$$

$\left(\sigma_{3}\right)_{0}$ is the value of $\sigma_{3}$ below which $\phi$ is independent of $\sigma_{3}$, and above which $\phi$ decreases as $\sigma_{3}$ increases, given by:

$$
\left(\sigma_{3}\right)_{0}=4 \cdot(1-e) \quad\left(\mathrm{kgf} / \mathrm{cm}^{2}\right)
$$

The function $g_{R}(\delta)$ is given as:

$$
\begin{aligned}
g_{R}(\delta)= & {\left[1.0-(0.13 \cdot e+0.235) \cdot\{(\delta / 90)-1\}^{2}\right] } \\
& \cdot J(e, \delta)+[(0.1 \cdot e+0.82) \\
& \left.-(3.19-3.65 \cdot e) \cdot(\delta / 90)^{2}\right] \\
& \cdot\{1-J(e, \delta)\}
\end{aligned}
$$

where,

$J(e, \delta)=$ a jump function defined as follows:
$J(e, \delta)=0$ when $\delta \leq(80 \cdot e-30)$

$J(e, \delta)=1.0$ when $\delta>(80 \cdot e-30)$

The original relationship between $g_{R}(\delta)$ and $\delta$ is shown in Fig. 21 of Tatsuoka et al. (1986) and Fig. 3 of Tatsuoka et al. (1990).

\section{Smooth Transition at Peak}

By using Eq. (39), smooth transition from $f(\gamma)$ to $g(\gamma)$ near the peak is attained by defining the power $s$ (Eq. 40) so that $g(\gamma)$ passes through a fixed point on a given $f(\gamma) \sim \gamma$ relation (GHE). In this study, this point was selected at $R=0.8 \cdot R_{\max }$ (Fig. 15), at which most of the measured relation start deviating from their fitted GHE relations (see Fig. 15). Then, using a three-point fitting method, the parameter $\mathrm{s}$ is obtained as:

$$
s=\log \left(\frac{R_{1}-1.0}{R_{\max }-1.0}\right) / \log \left(\frac{2 \sqrt{\gamma_{1} \cdot \gamma_{f}}}{\gamma_{1}+\gamma_{f}}\right)
$$

where $\gamma_{1}$ is $\gamma$ obtained by substituting $R=0.8 \cdot R_{\max }$ into $f(\gamma)(\mathrm{GHE})$.

For $p(\gamma)$, the following function, which satisfies $d p\left(\gamma_{f}\right) / d \gamma=0$, was selected:

$$
p(\gamma)=\left[\cos \left\{\pi \cdot\left(\frac{\gamma}{\gamma_{f}}\right)^{t}\right\}+1\right] / 2
$$

The constant $t$ is obtained from an arbitrarily chosen condition $p\left(\gamma_{1}\right)=0.9$ as:

$$
\boldsymbol{t}=\log \{\arccos (0.8) / \pi\} / \log \left\{\frac{\gamma_{1}}{\gamma_{f}}\right\}
$$

Using this value of $t, p(\gamma)$ is nearly 1.0 for $\gamma$ less than $\gamma_{1}$. Fig. 15 shows an example of fitting for the pre-peak part up to the peak stress state of the data shown in Fig. 9. The post-peak part of $R(\gamma)$ will be explained below.

Tatsuoka et al. (1990) showed a set of PSC data obtained by the photogrametric method, which indicates that already before the peak stress state, noticeable strain localization as a sign of the evolution of shear band(s) appears. In modelling the pre-peak and post-peak behaviour, however, it was assumed that the deformation of PSC specimen is homogeneous up to the peak state, and the strain localization to a shear band, or bands, 
starts suddenly at the peak stress state. Of course, this is only an approximation, but may be acceptable at the current stage. Based on the observation made by Tatsuoka et al. (1991), the post-peak stress-strain relation for $\gamma \geq \gamma_{f}$ in a shear band was modelled by Tanaka (1988) as:

$$
R=R_{r}+\left(R_{\max }-R_{r}\right) \cdot \exp \left[-\left(\frac{\gamma-\gamma_{f}}{\varepsilon_{r}}\right)^{2}\right]
$$

where,

$$
R_{r}=\frac{1+\sin \phi_{r}}{1-\sin \phi_{r}}
$$

$\phi_{r}=35.0^{\circ}$ (the typical residual angle of $\phi$ in PSC for Toyoura Sand) and $\varepsilon_{r}=0.6$ (or $60 \%$ ). Then, during post-peak strain-softening, the shear strain averaged for the specimen height is a function of the ratio of the shear band width to the specimen height, $\boldsymbol{H}$ (therefore, a function of the ratio of the particle mean diameter $D_{50}$ to $\boldsymbol{H}$ ), since strain is localized in a shear band (or bands), while the deformation in the zone outside a shear band (or bands) is elastic rebound exhibiting very small negative shear strain increments (Tatsuoka et al., 1990). In this study, the post-peak stressstrain relations were obtained as follows. Based on the observation (Tatsuoka et al., 1986), a single shear band was assumed in each specimen. Then, the post-peak shear strain increment $\Delta \gamma_{a v}$ averaged for the specimen height $\boldsymbol{H}$ is obtained from the shear strain increment $\Delta \gamma_{s b}$ obtained from Eq. (53) by using the ratio of the shear band area to the specimen area as:

$$
\Delta \gamma_{a v}=\frac{w / \cos \theta}{H} \cdot \Delta \gamma_{s b}
$$

where $w$ is the shear band width $(\approx 0.3 \mathrm{~cm}$ for Toyoura Sand) and $\theta$ is the angle of shear band direction relative to the $\sigma_{3}$ direction. Here, an approximate value of $\theta=45^{\circ}+\phi / 2$ was used.

\section{MODELLING FOR ANISOTROPICALLY CONSOLIDATED SAND}

A method to obtain stress-strain relations for anisotropically consolidated specimens by transforming those for the isotropically consolidated specimens is described below. In Fig. 19 , there are two curves $y_{1}=f_{\text {iso }}(x)$ and $y_{2}$ for isotropically and anisotropically consolidated specimens, respectively. Based on the test results presented in the following, $y_{2}$ was derived from $f_{\text {iso }}(x)$ by the following conditions:

when $y_{2} \geq m y_{a}, d y_{2} / d x$ is rejoining to $d f_{\text {iso }}(x)$ /dx; namely,

$$
y_{2}=f_{i s o}\left(x+x_{b}^{*}-x_{b}\right)
$$

when $y_{a}<y<m y_{a}$,

$$
y_{2}=f_{a n}(x)
$$

$f_{a n}(x)$ (Eq. 57) is subjected to the following boundary conditions:

$f_{a n}(0)=y_{a}$

$f_{a n}\left(x_{b}\right)=m y_{a}$

$d f_{a n}\left(x_{b}\right) / d x_{1}=d f_{\text {iso }}\left(x_{b}^{*}\right) / d x_{2}$

The derivation of transformation is as follows. Fig. 20 illustrates the relationships between the ratio of the tangent modulus $G_{\tan } / G_{\max }=d y / d x$ and the stress level $y$ for the

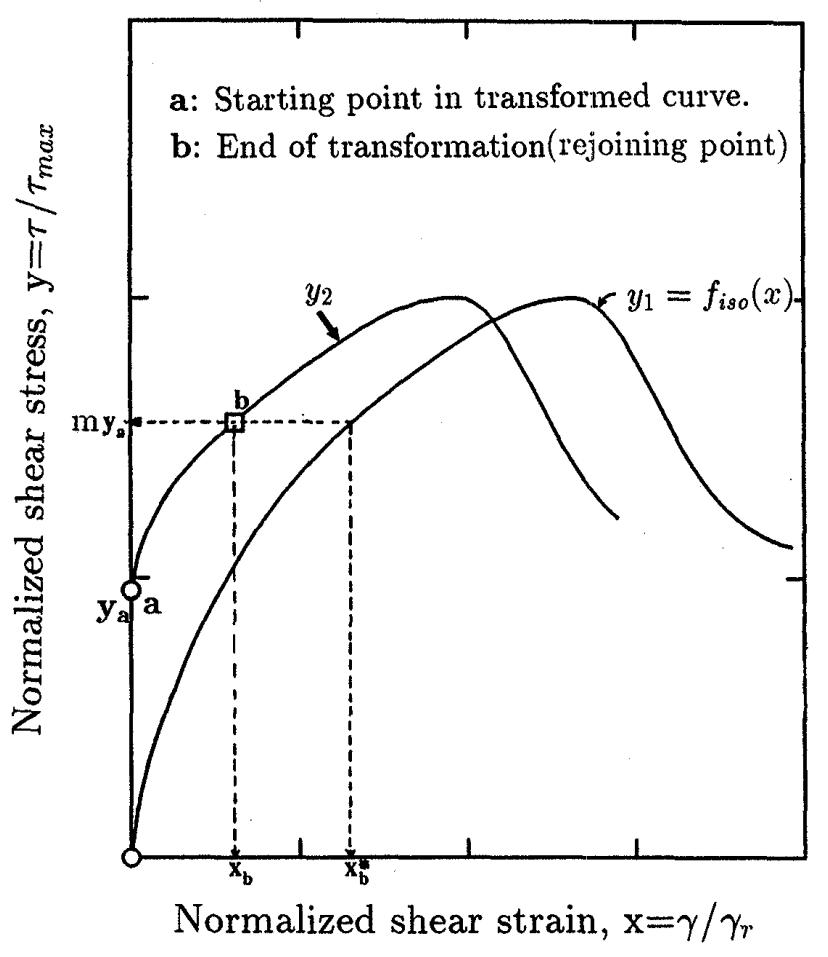

Fig. 19. Illustration of typical stress-strain curves for isotropic and corresponding anisotropic specimens and the specific transforming points 
two relations shown in Fig. 19. It was first assumed that the value of $d y / d x$ at the start of shearing is the same and equal to 1.0 between the two. This assumption is based on several experimental findings that at the same average value of the two principal stresses (i.e., the major and minor principal stresses) in the plane of shearing, the initial and maximum shear modulus $G_{\max }$ during monotonic loading PSC tests was rather independent of the stress ratio $K_{c}=\sigma_{3} / \sigma_{1}$ during consolidation, and also that the value of $G_{\max }$ during monotonic loading torsional shear tests is not affected by the initial shear stresses during consolidation (Tatsuoka and Shibuya, 1992; Shibuya et al., 1992). Then, the stress levels $y_{2}$ and $y_{1}$ for the same tangent modulus $d y / d x$ are obtained. By using the data of PSC tests at $\sigma_{3}=0.5 \mathrm{kgf} / \mathrm{cm}^{2}$ performed by Abe (1989), the difference $y_{2}-y_{1}$ was plotted against $y_{1}$ as shown in Fig. 21. For the dense and loose specimens, $K_{c}=1.0$ and $0.356\left(y_{a}=0\right.$ and 0.449$)$ and $K_{c}=1.0$ and 0.432 $\left(y_{a}=0\right.$ and 0.332), respectively, were employed (see Fig. 19 of Shibuya et al., 1992). It may be seen from Fig. 21 that for each case,

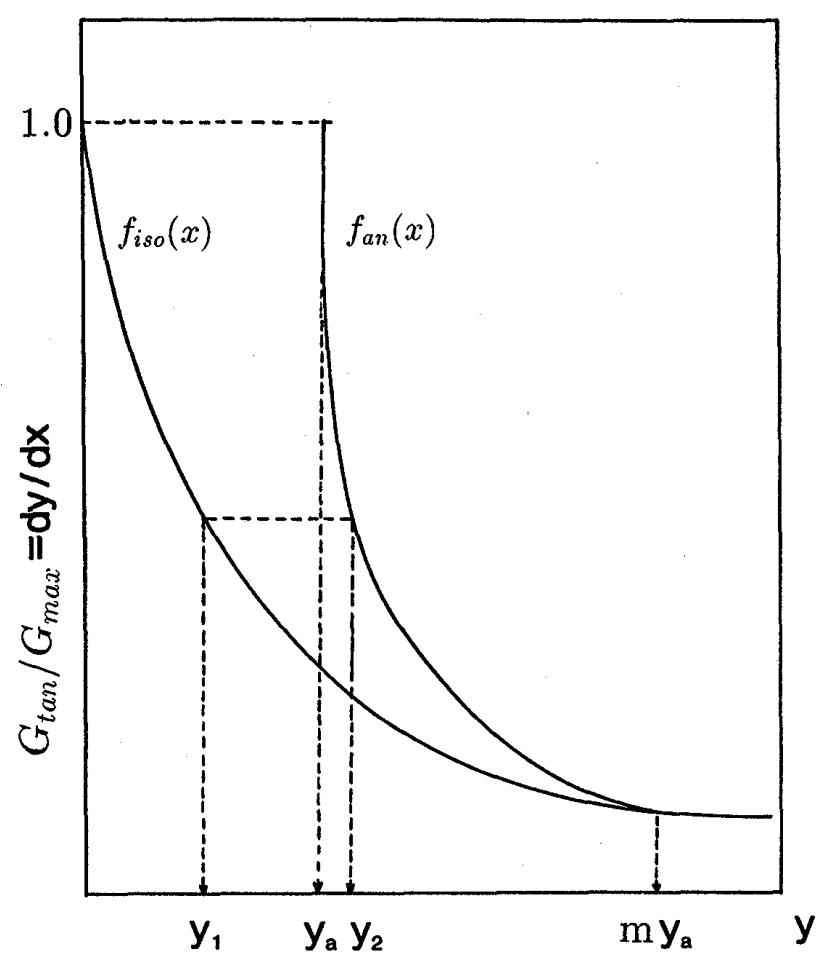

Fig. 20. $G_{\text {tan }} / G_{\max }$ plotted against the stress level $y$ and the specific transforming points

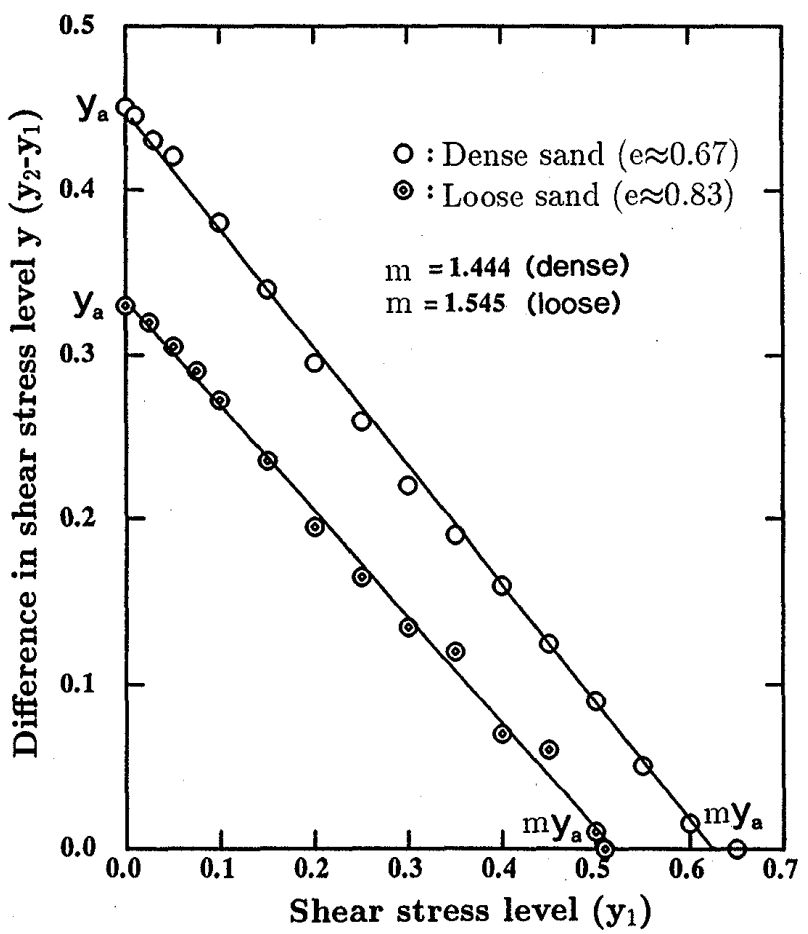

Fig. 21. Relationship between difference in shear stress level $y_{2}-y_{1}$ for the same $G_{\tan } / G_{\max }$ and shear stress level $\left(y_{1}\right)$ for isotropic and anisotropic samples in PSC (Abe, 1987)

the relation is a straight line, which can be expressed by:

$$
\begin{gathered}
\frac{y_{2}-y_{1}}{y_{a}}+\frac{y_{1}}{m y_{a}}=1 \\
\text { or, } \quad y_{1}=\left(y_{2}-y_{a}\right) \frac{m}{m-1} \\
\text { or, } y_{2}=y_{a}+\frac{m-1}{m} y_{1}
\end{gathered}
$$

It was assumed that the relations shown in Fig. 21 are independent of $\delta$ and $\sigma_{3}$. Referring to Fig. 22, Eq. (62) shows the rule for relating the coordinate $\left(x_{1}, y_{1}\right)$ of point $c$ on the original curve $y_{1}$ and the transformed one $\left(x_{2}\right.$, $y_{2}$ ) of point $d$ on the transformed curve $y_{2}$. Noting that $x_{2}$ is a function of $x_{1}$, we obtain by differentiating Eq. (62) with respect to $x_{1}$ :

$$
\left(\frac{d y_{1}}{d x_{1}}\right)_{a t x_{1}}=\left(\frac{d y_{2}}{d x_{2}}\right)_{a t x_{2}}\left(\frac{d x_{2}}{d x_{1}}\right) \frac{m}{m-1}
$$

Noting that the tangent stiffnesses $d y_{1} / d x_{1}$ and $d y_{2} / d x_{2}$ are the same, we obtain: 


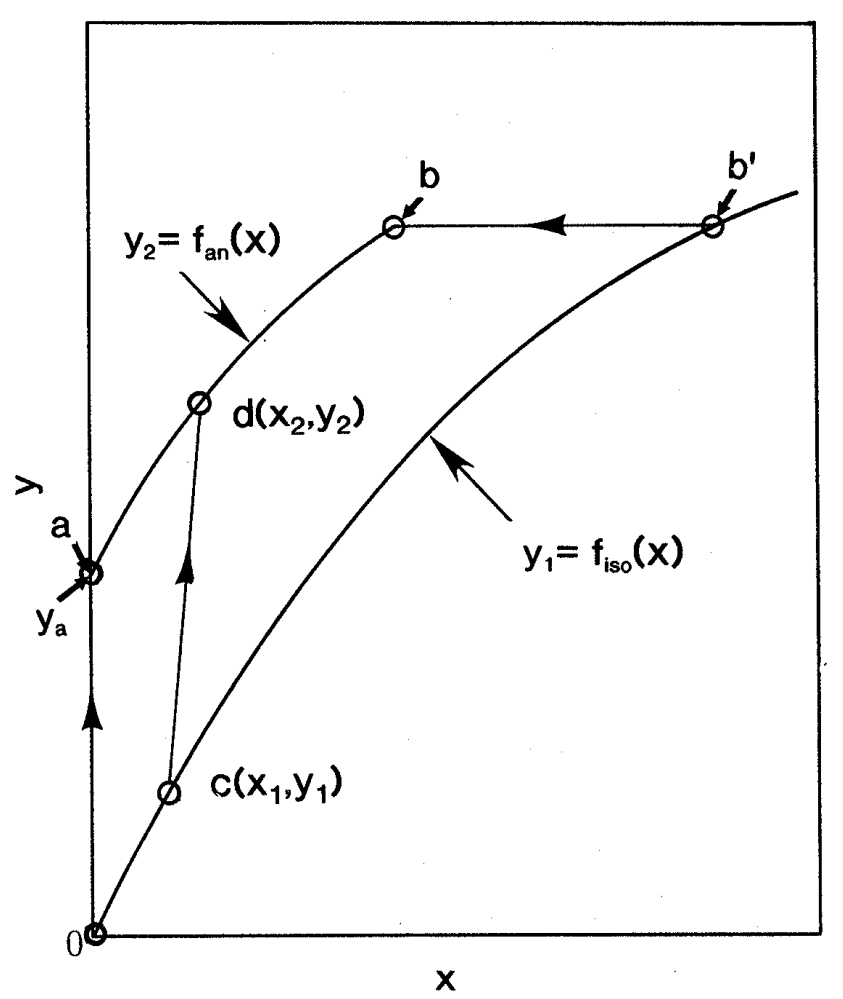

Fig. 22. Schematic diagram showing the transformation rule

$$
d x_{1}=\frac{m}{m-1} d x_{2}
$$

With $\left(x_{1}\right)_{\text {initial }}=\left(x_{2}\right)_{\text {initial }}=0$, we obtain:

$$
x_{1}=\frac{m}{m-1} x_{2}
$$

By substituting Eqs. (62) and (65) into Eq. (57), we obtain:

$\left(y_{2}-y_{a}\right) \frac{m}{m-1}=y_{1}=f_{\text {iso }}\left(\frac{m}{m-1} x_{2}\right) \quad\left(=f_{a n}(x)\right)$

or $y_{2}=y_{\mathrm{a}}+\frac{m-1}{m} f_{\text {iso }}\left(\frac{m}{m-1} x_{2}\right)$

Note that Eq. (66) is a somehow general transforming rule which can be rewritten as:

$$
y_{2}=y_{a}+n \cdot f_{i s o}\left(\frac{x_{2}}{n}\right)
$$

where the parameter $n$ is equal to $(m-1) / m$. In Fig. 23, the curve $y_{2}$ between points $a$ and $b$ in Fig. 22 has been moved right to the curve $y_{2}$

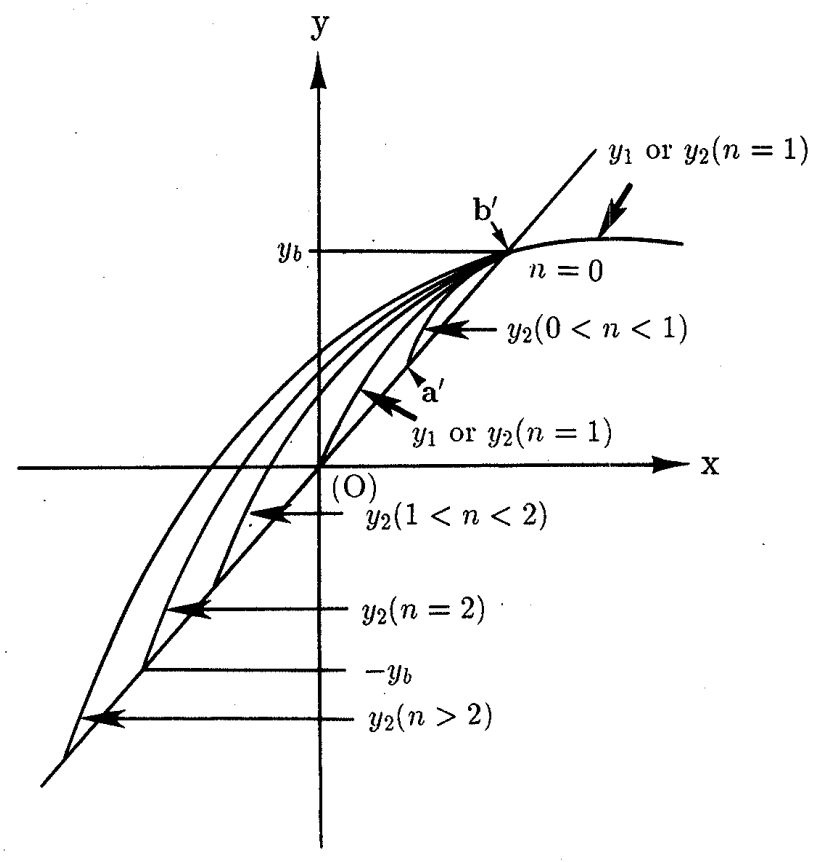

Fig. 23. General transformation rule

between points $\boldsymbol{a}^{\prime}$ and $\boldsymbol{b}^{\prime}$. Then, point $\boldsymbol{a}^{\prime}$ and $\boldsymbol{b}^{\prime}$ and the origin $\mathrm{O}$ are located on a single straight line. When the value of $n$ is changed, the following different curves having one end at point $b^{\prime}$ and the other end at point $a^{\prime}$ located on this straight line are obtained, transformed from the original curve $y_{1}$ located between points $O$ and $b^{\prime}$. When $n=0$, the curve shrinks to one point, point $\boldsymbol{b}^{\prime}$. When $n$ is between 0 and 1 , curves located between points $O$ and $b^{\prime}$ are obtained. When $n$ is equal to 1.0 , no transformation is made. When $n$ is larger than 1.0, curves larger than the original one are obtained. When $n$ is equal to 2 , the transformation is the well-known Masing's second rule (Pyke, 1979).

Two other typical models to obtain the stress-strain relations for anisotropically consolidated specimens by transforming those for isotropically consolidated ones are denoted by Models 1 and 2 in Fig. 24. Model 1 assumes that the stress-strain relations during shearing is independent of the stress ratio during consolidation, thus the tangent modulus is only a function of the current stress level $y$. This model under-estimates the stiffness at the beginning stage of shearing for anisotropically 


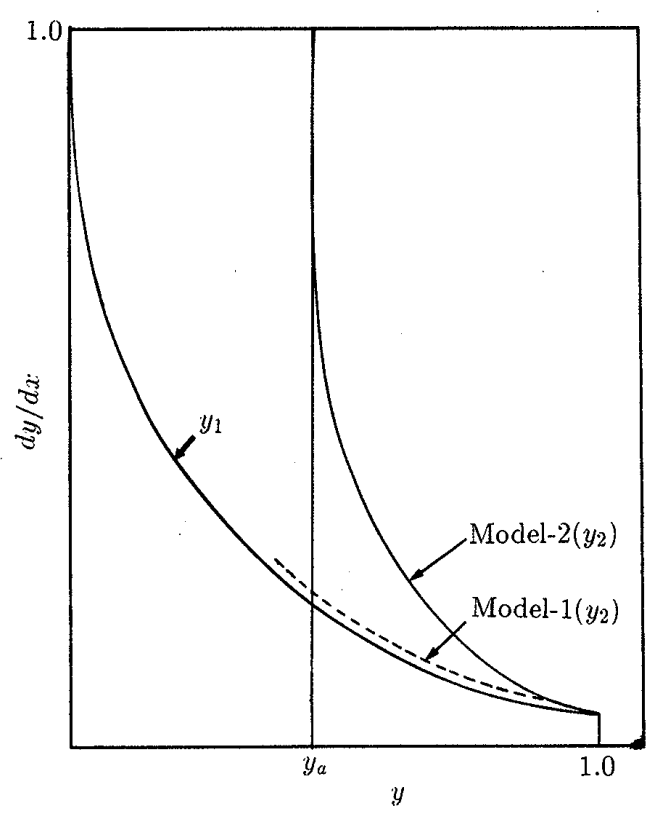

Fig. 24. Two other models to obtain the stress-strain relations for anisotropically consolidated specimens by transforming those for isotropically consolidated ones

consolidated specimens. Model 2 distorts the stress-strain relations for isotropically consolidated specimens for the entire range from $y_{a}$ to the failure $(y=1.0)$ with the same initial stiffness between the anisotropically and isotropically consolidated specimens (e.g., Sekiguchi and Ohta, 1977). Model 2 overestimates the stiffness when approaching to the failure state.

In summary, the equation before rejoining $\left(1 / K_{0}<R_{a n}<m / K_{0}\right)$ in terms of $R_{a n}=\sigma_{1} / \sigma_{3}$ and $\gamma$ for $K_{0}$-consolidated specimens is as follows:

$R_{a n}=\frac{1}{K_{0}}+\frac{m-1}{m} \cdot R_{i s o}\left(\frac{m}{m-1} \cdot \gamma\right)$

The value of $\boldsymbol{m}$ for $K_{0}$ consolidated specimens are around 1.5 (see Fig. 21). For the value of $K_{0}$,

$$
K_{0}=0.52 \cdot e
$$

may be used, which is the empirical equation obtained for air-pluviated Toyoura Sand (Okochi and Tatsuoka, 1984). After rejoining $\left(\left(m / K_{0}\right) \leq R_{a n}<R_{\max }\right)$, including the post-peak state $\left(\gamma>\gamma_{f}\right)$ :

$$
R_{a n}=R_{i s o}\left(\gamma+\gamma_{b}^{*}-\gamma_{b}\right)
$$

where $\boldsymbol{R}_{\text {iso }}$ is the equation for isotropically consolidated specimens, and $\gamma_{b}$ and $\gamma_{b}^{*}$ are the shear strains for anisotropic and isotropically consolidated specimens corresponding to $x_{b}$ and $x_{b}^{*}$ (see Fig. 19).

\section{SOME EXAMPLES OF SIMULATION}

Finally, we will show some working examples based on the formulation of the stressstrain relation of Toyoura Sand. Figs. 25 through 27 show the comparison of back predicted stress-strain curves from this model with the experimental curves for isotropically consolidated specimens (shear strain have been corrected for $\mathrm{BE}$ ). In obtaining the postpeak stress-strain relations, the specimen height $H$ of $10.5 \mathrm{~cm}$ was used. A reasonable agreement between arbitrarily chosen experimental data and prediction may be seen. The difference is due to the scattering of the

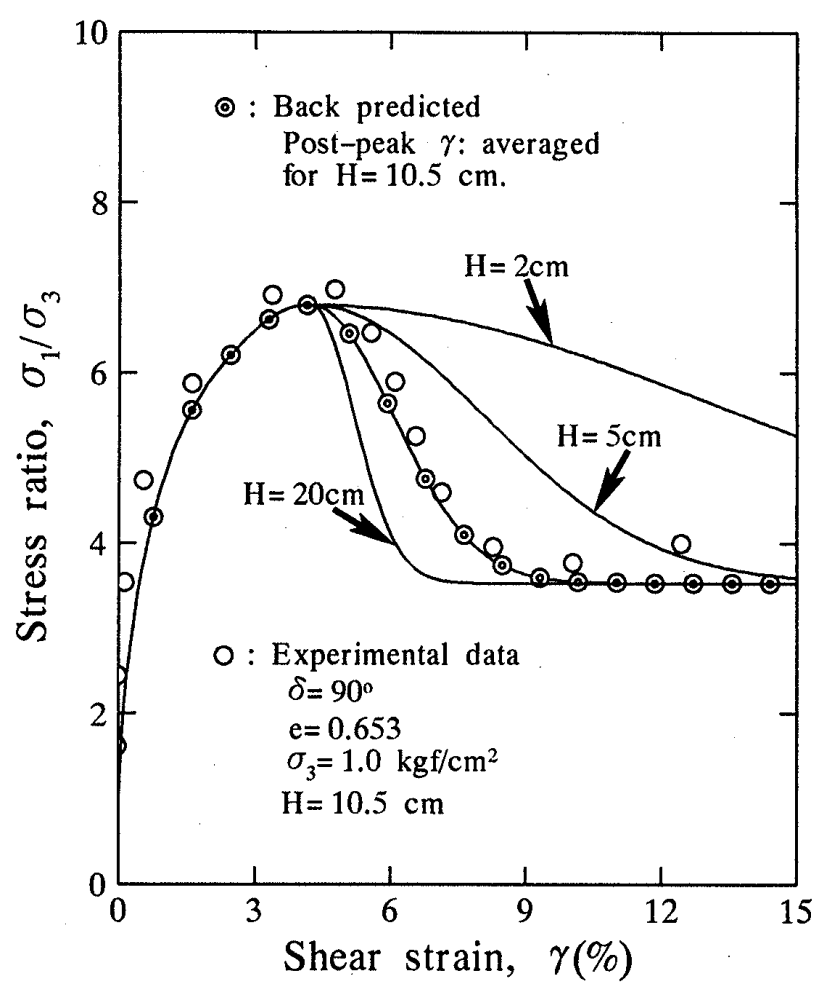

Fig. 25. Measured and back-predicted curves for PSC test-example 1, also showing the effect of sample height, $H$ 


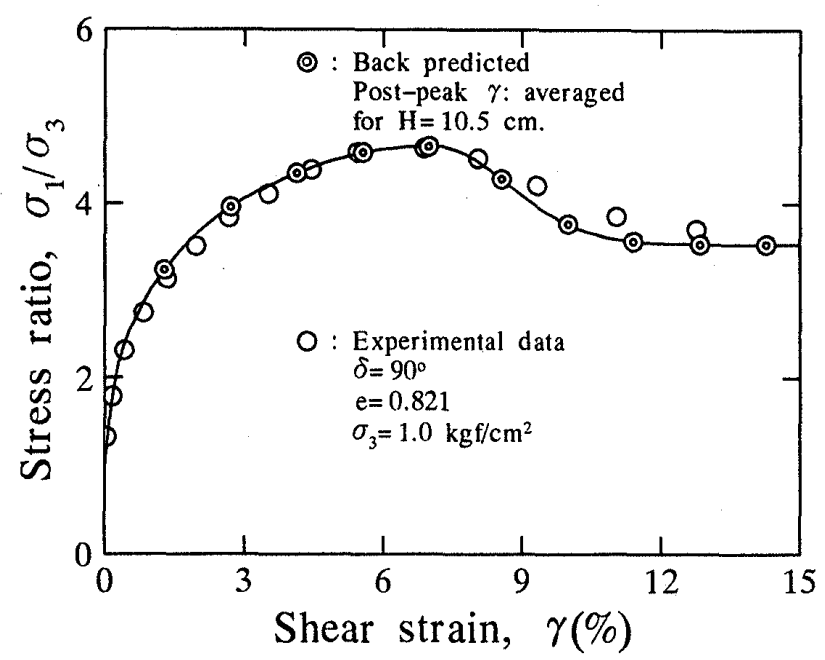

Fig. 26. Measured and back-predicted curves for PSC test-example 2

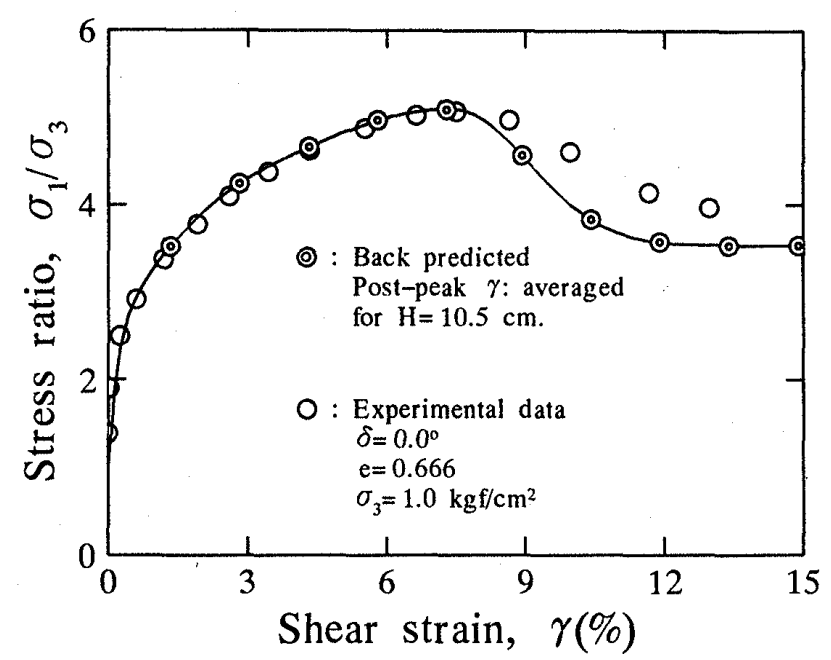

Fig. 27. Measured and back-predicted curves for PSC test-example 3

original data. In Fig. 25, the effect of $H$ on the post-peak stress-average strain relation is also demonstrated. Figs. 28 through 30 show some examples of stress-strain relations which are depending on void ratio $(e)$, the angle of bedding plane orientation $(\delta)$ with respect to $\sigma_{1}$ direction, the confining pressure $\left(\sigma_{3}\right)$ and the consolidation stress ratio, generated by using the proposed model with $H=10.5 \mathrm{~cm}$.

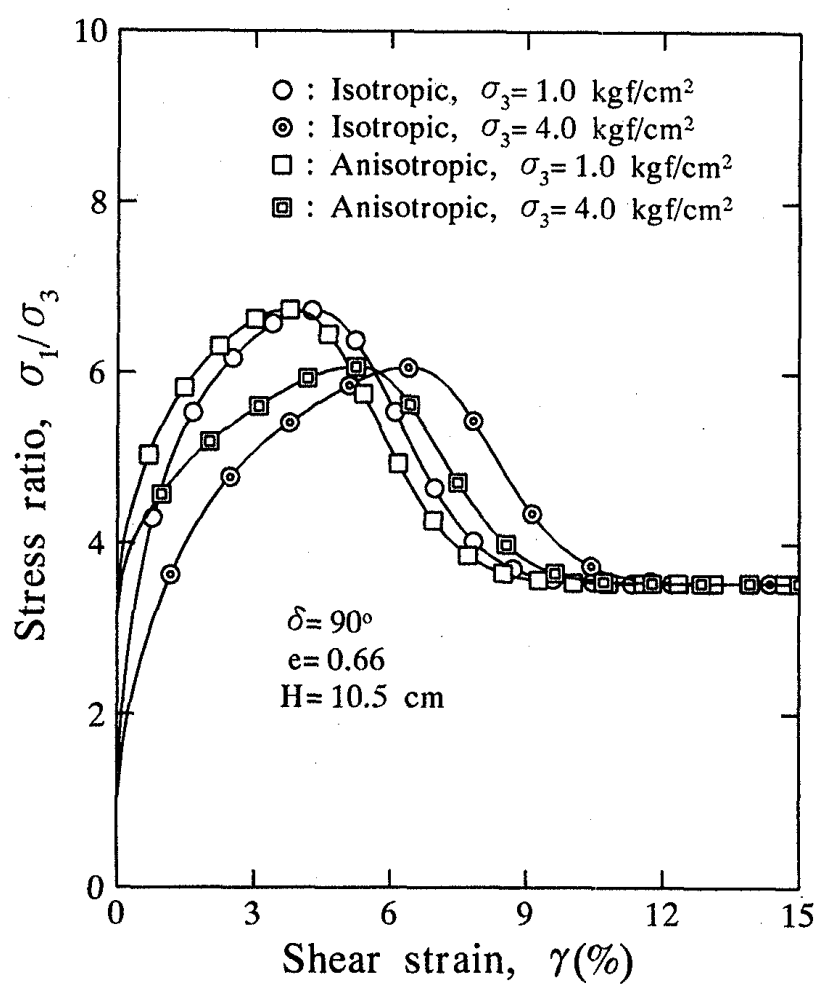

Fig. 28. Dependency on pressure level by the proposed model

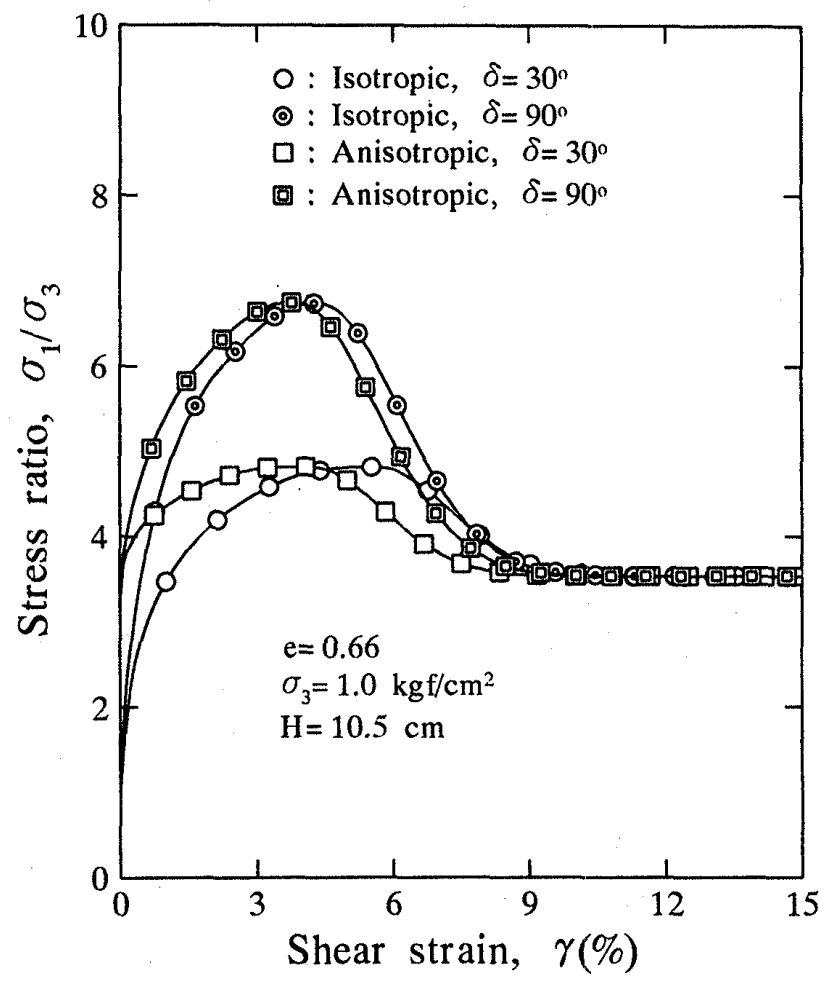

Fig. 29. Dependency on strength anisotropy by the proposed model 


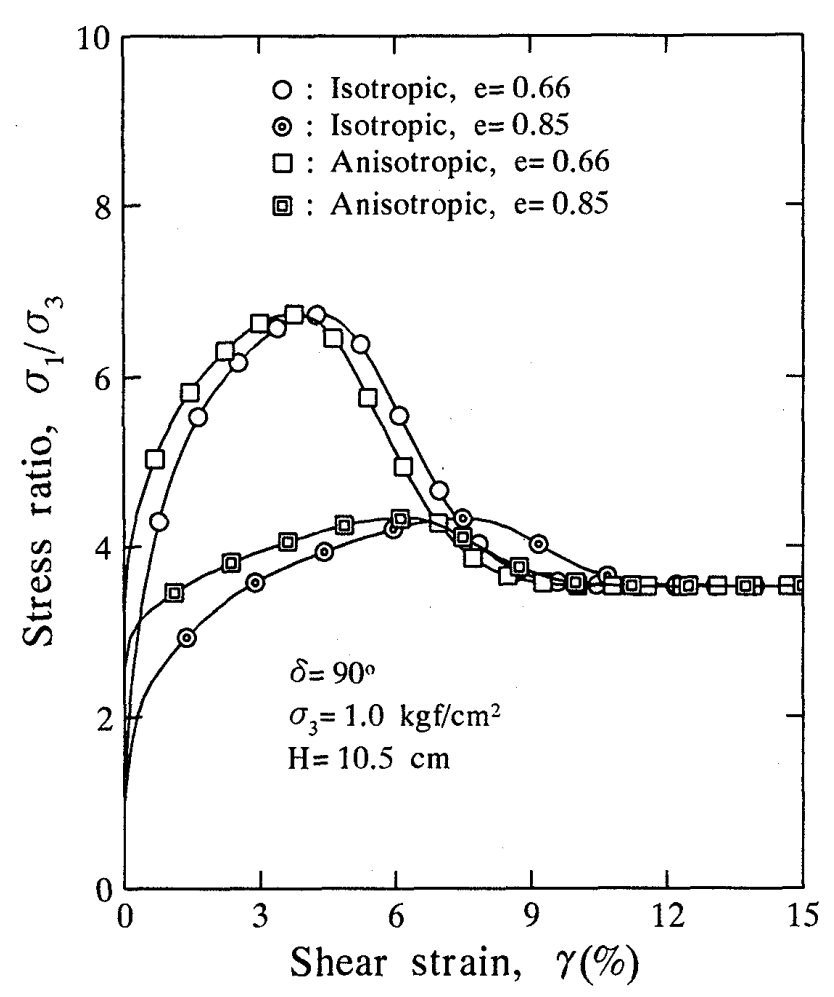

Fig. 30. Dependency on initial void ratio by the proposed model

\section{CONCLUSIONS}

The soil model described in this paper is exclusively applicable to a particular type of stress-strain relation, namely, the shear stressshear strain relations in plane strain compression at a constant $\sigma_{3}$ and for a particular type of soil, namely, Toyoura Sand. Despite the above, this approach taking into account the effects of many major factors can be applied to general types of soils. In particular, the generalized hyperbolic equation (GHE, Eq. 12 or Eq. 17) used herein is able to model a given stress-strain relation from very small strains $\left(\sim 10^{-6}\right)$ up to near the peak stress state for almost any kind of non-linear material (Siddiquee, 1991). Further, the anisotropic strength and deformation characteristics, post-peak strain softening associated with strain localization into a shear band, and the effect of anisotropic consolidation are modelled in a rational way.

This model lacks simplicity. However, this drawback can be alleviated by being coded in a computer program, by which any stressstrain relation for a given condition in terms of the void ratio, $\sigma_{3}, \delta$, the consolidation stress ratio and the element size (or specimen size) can be generated. This model has already been successfully used in the FEM simulation of the results of a series of plane strain bearing capacity model tests of strip footing on Toyoura Sand (Tatsuoka et al., 1991, 1992, Siddiquee, 1991, Siddiquee et al., 1991, 1992). In particular, the scale effect in the bearing capacity as observed in tests performed under gravitational acceleration using different sizes of footing, the pressure level effect as observed in centrifuge tests varying the acceleration level using one size of footing, and the particle size effect, which is the difference between the above two, were successfully simulated.

\section{ACKNOWLEDGEMENTS}

Equations (40) and (53) were suggested by Prof. T. Tanaka, of Meiji University.

\section{REFERENCES}

1) Abe, F. (1989): "Deformation characteristics of sand in plane strain compression at small strain levels," Master thesis, University of Tokyo (in Japanese).

2) Arthur, J. R. F. and Menzies, B. K. (1972): “Inherent anisotropy in sand," Géotechnique, Vol. 22, No. 1, pp. $115-128$.

3) Duncan, J. M. and Chang, C. Y. (1970): "Nonlinear analysis of stress and strain in soils," Journal of Soil Mechanics and Foundation Division, Proc. ASCE, Vol. 96 (SM5), pp. 1629-1653.

4) Goto, S. (1976): "Strength and deformation characteristics of granular materials in triaxial tests,"' Ph.D. thesis, University of Tokyo.

5) Goto, S., Tatsuoka, F., Shibuya, S., Kim, Y. S. and Sato, Y. (1991): "A simple gauge for local small strain measurements in the laboratory," Soils and Foundations. Vol. 31, No. 1, pp. 169-180.

6) Iwasaki, T. and Tatsuoka, F. (1977): "Effects of grain size and grading on dynamic shear moduli of sands," Soils and Foundations, Vol. 17, No. 3, pp. 19-35.

7) Iwasaki, T., Tatsuoka, F. and Takagi, Y. (1978): "Shear modulus of sands under cyclic tortional shear loading," Soils and Foundations, Vol. 18, No. 1, pp. 39-56.

8) Kondner, R. B. (1963): "Hyperbolic stress-strain response: cohesive soils," Journal of SMF Div., 
Proc. ASCE, Vol. 89 (SM1), pp. 115-143.

9) Nakamura, S. (1987): "Strain distribution of sand specimen in Plane Strain Compression tests," Master thesis, University of Tokyo (in Japanese).

10) Oda, M. (1972): "Initial fabrics and their relations to mechanical properties of granular materials," Soils and Foundations, Vol. 12, No. 1, pp. 17-36.

11) O-kochi, Y. and Tatsuoka, F. (1984): "Some factors affecting $\mathrm{K}_{0}$-values of sand in triaxial cells," Soils and Foundations, Vol. 24, No. 3, pp. 52-68.

12) Park, C. S. (1990): "Anisotropy in deformation and strength properties of sands in plane strain compression," Master thesis, University of Tokyo (in Japanese).

13) Park, C. S. and Tatsuoka, F. (1994): "Anisotropic strength and deformation of sands in plane strain compression," Proc. XIII ICSMFE, New Delhi, India.

14) Prevost, J. H and Keane, C. M. (1989): “'Shear stressstrain curve generation from simple material parameters," Journal of Geotechnical Engineering, ASCE, Vol. 116, No. 8, pp. 1255-1263.

15) Pyke, R. (1979): "Nonlinear soil models for irregular cyclic loadings," Jour. of GE Div., Proc. of ASCE, Vol. 105, No. GT6, pp. 715-726.

16) Sekiguchi, H. and Ohta, H. (1977): "Induced anisotropy and time dependency in clays," Proceedings of Specialty Session 9, 9th Internation Conference on Soil Mechanics and Foundation Engineering, Tokyo, pp. 229-238.

17) Shibuya, S., Tatsuoka, F., Abe, F., Kim, Y.-S., Park, C.-S. and Mukabi, J. N. (1991a): "A new look into stress and strain relation of soils and rocks," Proc. 9th Asian Regional Conference on SMFE, Bangkok, Vol. I, pp. 63-66.

18) Shibuya, S., Tatsuoka, F., Abe, F., Teachavorasinskun, S. and Park, C. S. (1991): "Elastic properties of granular materials measured in the laboratory," Proc. of 10th European Regional Conference on SMFE, Florence, Vol. 1, pp. 163-166.

19) Shibuya, S., Tatsuoka, F., Teachavorasinskun, S., Kong, X. J., Abe, F., Kim, Y. S. and Park, C. S. (1992): "Elastic deformation properties of geomaterials", Soils and Foundations, Vol. 32, No. 3, pp. 26-46.

20) Siddiquee, M. S. A. (1991): "Finite element analysis of settlement and bearing capacity of footing on sand,"' Master thesis, University of Tokyo, Oct.

21) Siddiquee, M. S. A., Tanaka, T. and Tatsuoka, F. (1991): “A FEM simulation of model footing tests on sands,"' Proc. of 26th Japan National Conference on SMFE, Nagano, pp. 1309-1312.

22) Siddiquee, M. S. A., Tanaka, T and Tatsuoka, F. (1991): "A numerical simulation of bearing capacity of footing on sand." Proc. of 27th Japan National Conference on SMFE, Nagano, pp. 1413-1416.

23) Tanaka, T. and Kawamoto, O. (1988): "Three dimensional finite element collapse analysis for foundations and slopes using dynamic relaxation," Proc. of Numerical Methods in Geomechanics, Insbruch, pp. 1213-1218.

24) Tanaka, T. (1988): "Private communication'”

25) Tatsuoka, F. (1984): "Discussion on Yu Peiji and Richart, F. E. and Jr., (1984)," ASCE Journal of Geotechnical Engineering Division, Vol. 2, No. 3, pp. 1155-1157.

26) Tatsuoka, F., Molenkamp, F., Torii, T. and Hino, T. (1984): "Behaviour of lubrication layers of platens in element tests," Soils and Foundations, Vol. 24, No. 1, pp. 113-128.

27) Tatsuoka, F., Sakamoto, M., Kawamura, M. and Fukushima, S. (1986): "Strength and deformation characteristics of sand in plane strain compression at extremely low pressures," Soils and Foundations, Vol. 26, No. 1, pp. 65-85.

28) Tatsuoka, F. (1987): "Discussion on the paper by Bolton, M. D. (1986)," Géotechnique, Vol. 37, No. 2, pp. 219-226.

29) Tatsuoka, F., Nakamura, S., Huang, C. C. and Tani, K. (1990): "Strength anisotropy and shear band direction in plane strain tests of sand," Soils and Foundations, Vol. 30, No. 1, pp. 35-54.

30) Tatsuoka, F., Okahara, M., Tanaka, T., Tani, K., Morimoto, T. and Siddiquee, M. S. A. (1991): "Progressive failure and particle size effect in bearing capacity of a footing on sand," Geotechnical Engineering Congress-ASCE, Geotechnical Special Publication 27, Vol. 2, pp. 788-802.

31) Tatsuoka, F. and Shibuya, S. (1992): “Deformation characteristics of soils and rocks from field and laboratory tests,"' Keynote Lecture for Session No. 1, Proc. 9th Asian Regional Conf. on Soil Mechanics and Foundation Engineering, Bangkok, 1991, Vol. 2., pp. 101-170.

32) Tatsuoka, F. and Siddiquee, M. S. A., Tanaka, T. and Okahara, M. (1992): "A new aspect of a very old issue: Bearing capacity of footing on sand," Discussion for Session 3, Proc. 9th Asian Regional Conf. on Soil Mechanics and Foundation Engineering, Bangkok, 1991, Vol. 2., pp. 358. 